\title{
Expansion of the Lower Arch Concurrent with Rapid Maxillary Expansion
}

\author{
Robin Sandstrom Papaconstantinou \\ Loyola University Chicago
}

Follow this and additional works at: https://ecommons.luc.edu/luc_theses

Part of the Orthodontics and Orthodontology Commons

\section{Recommended Citation}

Papaconstantinou, Robin Sandstrom, "Expansion of the Lower Arch Concurrent with Rapid Maxillary Expansion" (1981). Master's Theses. 3159.

https://ecommons.luc.edu/luc_theses/3159

This Thesis is brought to you for free and open access by the Theses and Dissertations at Loyola eCommons. It has been accepted for inclusion in Master's Theses by an authorized administrator of Loyola eCommons. For more information, please contact ecommons@luc.edu. cc) (†) $\odot$

This work is licensed under a Creative Commons Attribution-Noncommercial-No Derivative Works 3.0 License. Copyright (C) 1981 Robin Sandstrom Papaconstantinou 
EXPANSION OF THE LOWER ARCH CONCURRENT WITH RAPID MAXILLARY EXPANSION

by

Robin Sandstrom Papaconstantinou, D.D.S.

A Thesis Submitted to the Faculty of the Graduate School of Loyola University of Chicago in Partial Fulfillment of the Requirements for the Degree of Master of Science July 1981 


\section{DEDICATION}

To my husband, Stavros, for sharing his love and for being an inspiration as my classmate, teacher and friend. 
To my parents for offering their greatest love and for instilling the importance of an education 


\section{ACKNOWLEDGEMENTS}

I would like to express my gratitude to those who contributed their help in the making of this thesis.

My sincere appreciation is extended to the following people:

Dr. Andrew Haas, for making this study possible by offering the invaluable material from his private practice, and giving me the incentive to pursue this investigation.

Dr. Lewis Klapper, for his advice and help in the development of this thesis and for the intellectual stimulation he provided as my teacher and advisor.

To the rest of the members of my committee, Dr. John Wortel and Dr. James Beery for their assistance and guidance in the completion of this study.

Dr. Stavros Papaconstantinou for the advice, constructive criticism and many hours of help devoted to this investigation.

Dr. Douglas Bowman for his guiding ideas regarding the statistics in this study.

Mr. Preston Bricker for the time dedicated helping with the computer and the statistics. 
Dr. Stephanos Karakussoglu for his assistance in setting up the digitizer and helpful ideas.

Dr. Richard Lang for his assistance in the proofreading of the manuscript.

To all my teachers and faculty members for their guidance during my orthodontic education.

Bernie Ciamarichello for her patience and endurance throughout the typing of this manuscript.

Mrs. Nan Glending and Mrs. Sharon Wood, and the staff in Dr. Haas' office for kindly helping me locate the necessary records.

Dr. Elias Harari for advising me to pursue a dental specialty.

A special note of gratitude to my friend Dr. Monus Albert for giving me his encouragement and motivation for pursuing my orthodontic training.

Finally, I would like to acknowledge my grandparents for their love and support throughout this period of my life. 
VITA

The author, Robin Sandstrom Papaconstantinou was born on April 22, 1956 in Moline, Illinois, the daughter of J. Robert Sandstrom, and Esther Cesarman.

Her elementary education and the first two years of her secondary education were received in Colegio, Columbia, Mexico City. In 1974, she completed her secondary education in Alianza Anglo-Mexicana, Mexico City.

In January, 1975, she entered the Dental School of the Universidad Tecnologica de Mexico, for a four year program, graduating in 1979 .

In July, 1979, she entered Loyola School of Dentistry, Orthodontic Department. In May, 1981, she completed a two-year post-graduate program leading to a Certificate of Specialty in orthodontics and a graduate program leading to a Master of Science in Oral Biology. 
TABLE OF CONTENTS

Page

ACKNOWLEDGEMENTS $\ldots \ldots \ldots \ldots \ldots \ldots \ldots \ldots \ldots \ldots \ldots \ldots \ldots \ldots \ldots$ iv

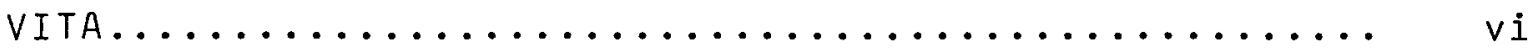

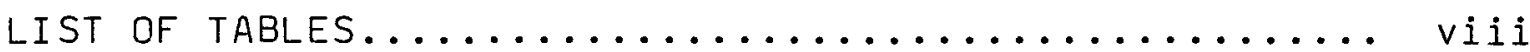

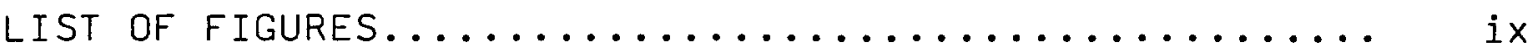

CONTENT OF APPENDIX........................ Xi

Chapter

I. INTRODUCTION.................... I

II. REVIEW OF RELATED LITERATURE............ 3

II . MATERIALS AND METHODS................ 21

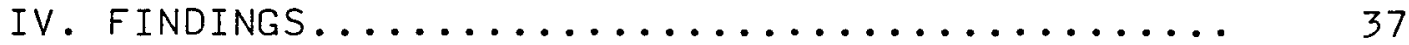

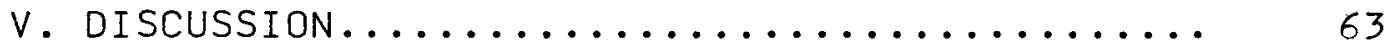

VI. SUMMARY AND CONCLUSION................ 75

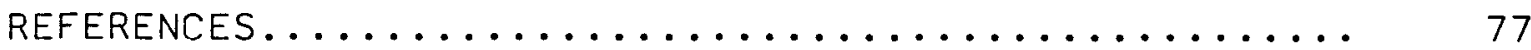

Appendix $\quad I$ A $\ldots \ldots \ldots \ldots \ldots \ldots \ldots \ldots \ldots \ldots \ldots \ldots \ldots \ldots$

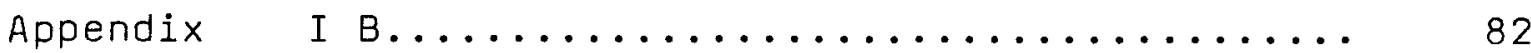

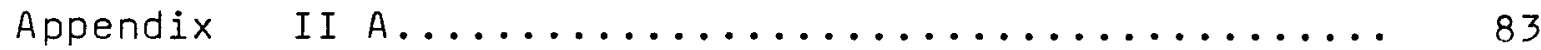

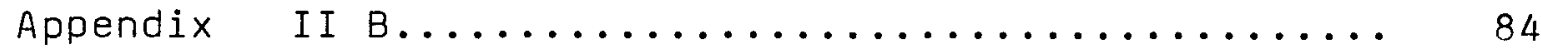

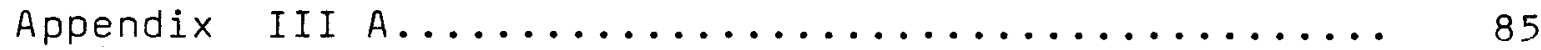

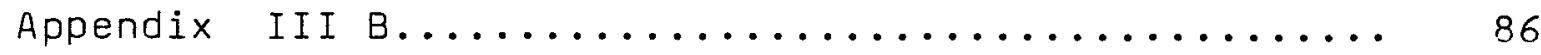

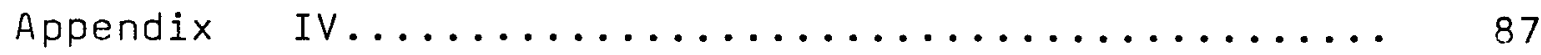


I. Summary of Material................. 25

II. Calculation of Facial Type Index.......... 35

III. Summary of the means of "Treatment", "Post-treatment"and "Resultant changes"........ 39

IV. Summary of Paired t tests of the "Treatment", "Post-treatment" and "Resultant changes" in

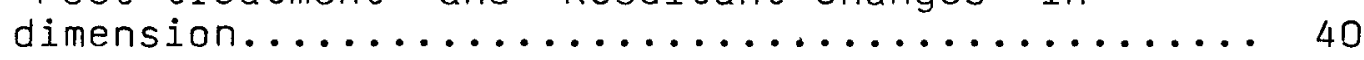

$\checkmark$. Average between the data of observers $A$ and $B \ldots .42$

VI. Summary of the two sample $t$ tests of the "Resultant changes" between the mesial and distal intermolar widths................. 49

VII. Summary of the correlations and t tests between the "Resultant changes" of the intercanine, mesial, and distal intermolar widths, and the Facial Type Indices of their

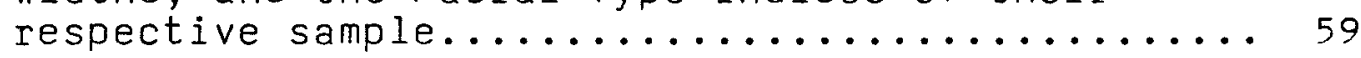

VIII. Summary of the correlations and $t$ tests between the "Resultant changes" of the intercanine, mesial, and distal intermolar widths, and the corresponding age of the

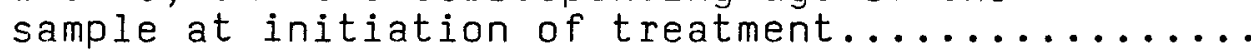




\section{LIST OF FIGURES}

Figure

Page

1. Illustration of the Palate Splitting Appliance...... 22

2. Intra-arch distances measured in this study....... 26

3. Illustration of digitizer set-up............. 28

4. Explanation of the Four Quadrant Graph........... 31

5. Series of landmarks located on lateral

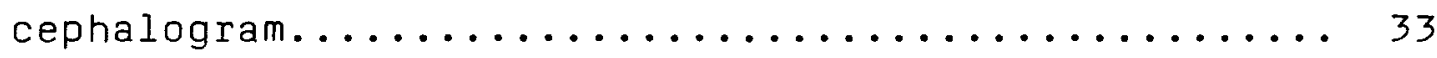

6. Series of angles measured on lateral

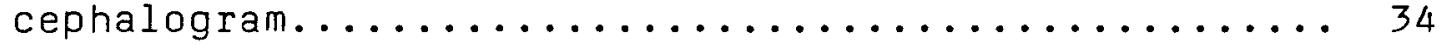

7. Diagram of the change in $\mathrm{mm}$. from the Initial to the post-treatment, to the Post-retention width, for the intercanine, mesial and distal intermolar dimensions..........4 43

8. "Treatment change" and "Post-treatment change" in intercanine width of 17 cases......... 45

9. "Resultant" intercanine width following treatment increase of the original

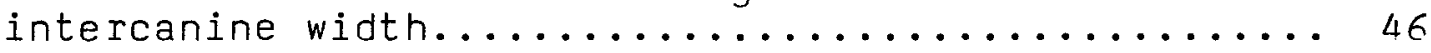

10. "Treatment change" and "Post-treatment change" in mesial intermolar width of 22 cases...... 50

11. "Treatment change" and "Post-treatment change" in distal intermolar width of 22 cases........... 51

12. Histogram of the frequency of the facial type distribution of the sample................... 55

13. Intercanine "Resultant change" in width, as related to the Facial Type Index of the

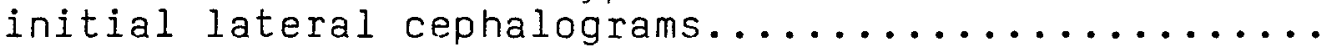


14. Mesial Intermolar "Resultant change" in width as related to the Facial Type Index of

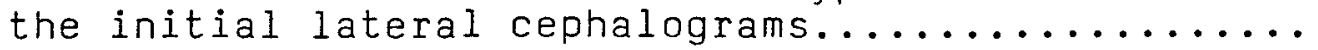

15. Distal Intermolar "Resultant change" in width as related to the Facial Type Index of

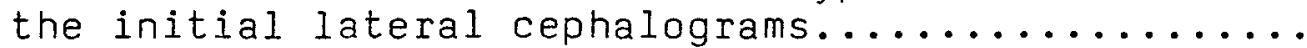

16. Intercanine "Resultant change" in width as related to the age of the sample at initiation of treatment...................6 60

17. Mesial and Distal Intermolar "Resultant change" in width as related to age of the sample at initiation of treatment. 
CONTENTS OF APPENDICES

Appendix

Page

I A Intercanine Dimensions - Observer A.......... 81

I B Intercanine Dimensions - Observer B.......... 82

I A Mesial Intermolar Dimensions - Observer A....... 83

I B Mesial Intermolar Dimensions - Observer B....... 84

II A Distal Intermolar Dimensions - Observer A...... 85

II B Distal Intermolar Dimensions - Observer B...... 86

IV Facial types according to cephalometric data..... 87 


\section{INTRODUCTION}

In the orthodontic field there is a great concern regarding the stability of treated cases, after the removal of retention appliances. It is assumed that beyond this stage there is no control over the case, and that its outcome does not lie "in hands" of the clinician. One of the most important factors affecting stability, is the expansion of the lower arch. The amount of expansion which can be exerted to relieve crowding, without expecting future relapse, must be considered before the initiation of treatment. This will determine quite often whether or not a case will undergo extraction. It is with this aspect that the present investigation deals with. If through some mechanism the orthodontist could achieve expansion of the lower arch, while still expecting stability, it would greatly influence his decision in borderline cases.

It has been shown in studies ${ }^{32}$ regarding the physiological development of the lower arch that its development is greatly influenced and to some degree 
dependent on the development of the upper arch itself. If this is so, is it not feasible to theorize that if the maxillary apical bases were expanded, this would cause a concomitant expansion of the lower arch? Furthermore, could a change in the muscle drape brought about through maxillary expansion allow the orthodontist to expand the lower arch expecting more stability than with normal orthodontic treatment?

The possibility of expanding the mandibular intercanine and intermolar dimensions and maintaining this expansion after treatment has been the subject of several investigations. However, one aspect of treatment expansion in intercanine width which has not been investigated is the effect of orthopedic maxillary expansion on the mandibular arch during and after orthodontic treatment.

I have been quite fortunate in being able to borrow all the material used in the present study from Dr. Haas, one of the foremost advocates of the maxillary expansion technique. With this, it will be possible to study what if anything, is the effect of rapid maxillary expansion on the lower dentition during treatment, and post-retention. 


\section{REVIEW OF LITERATURE}

In 1728, when Pierre Fauchard ${ }^{12}$ introduced the orthodontic arch wire, expansion was established as the main method of treatment in order to align teeth and aleviate crowding. At the time, treatment was viewed only from a mechanical aspect.

In 1907, with Angle's ${ }^{2}$ introduction of "normal occlusion," the basic philosophy started to shift from a mechanistic approach toward the awarness of the biological aspects of treatment. Nevertheless, his treatment approach was still based on the expansion of the arches. He advocated that by establishing a "normal" occlusion, with properly positioned teeth, apical bone growth would be stimulated by the normal functional forces and permanency of the teeth in their new positions would be achieved. Seemingly, the formation of alveolar bone was not completed until the position of the permanent teeth was determined. In contrast to this, during approximately the same period, Case $^{7}$ was one of the first to advocate extraction of teeth in an effort to avoid expansion and thus increase 
the stability of the remaining dentition following treatment. Lundstrom 27 , in 1925, introduced his apical base concept, stating that occlusal function alone could not control the form and amount of apical base. In contrast to Angle's belief, he sustained that the apical base itself was capable of affecting dental occlusion.

It is obvious that during the early years of modern orthodontics, two different philosophies of treatment were established. One advocated the expansion of the interdental width of the $\mathrm{arch}^{2}$, while the other sustained that consideration should be given to the limiting factors which may impede the liberal expansion of the $\operatorname{arch}^{27}$. Tweed ${ }^{44}$, in 1944, advocated excessive expansion, but finding this technique a "mistake" and recognizing the limitations of the supporting bone, he later resorted to the almost routine extraction of teeth. He believed teeth must be positioned over basal bone to be stable, and expansion should be avoided even if extraction became necessary. Hays Nance ${ }^{31}$, in 1947 , re-emphasized the necessity of having adequate basal support for all teeth. He mentioned the importance of determining the limitations of expansion of an individual case and also advocated extraction when necessary. He believed that though some expansion may be held post-retention, by no means could all be expected to remain. The largest permanent increase of the intercanine width ever achieved in his clinic was $2.6 \mathrm{~mm}$. 
These philosophies $27,31,44$ resulted in a variation of ideas and clinical rules regarding the establishment of arch width and its relationship to stability.

McCauley ${ }^{28}$, in 1944, was credited as the first to suggest the intercanine width should be maintained during treatment. Strang ${ }^{42}$, in 1946, concluded from observations of an undisclosed number of cases treated in his office, that stable results could only be obtained when the mandibular intercanine and intermolar widths were maintained. He stated further ${ }^{43}$, if the canine teeth were moved distally into the premolar extraction space, they could be expanded buccally to the same interarch distance held previously by the premolars. This view is supported by Howes 20,21 , who found basal bone from the first premolars forward, does not increase from age five onward and thus favored expansion of the arch in mixed dentition through distal movement of the cuspids. He also suggested in certain cases, expansion of the cuspids through their distal movement into the extraction site.

The next logical step after reviewing the theories on the most favorable position of the teeth within the arches, would be to see what has been proven clinically in retention studies. However, before proceeding to review what is possible with treatment, it is necessary to review the changes occuring in the lower arch as a result of growth without the influence of treatment. 
Reports $4,22,29,30,40$ on the physiological

development of the lower arch have indicated that during the transition from mixed to permanent dentition, there is overall an increase in arch width, with the anterior portion of the arch becoming a segment of a larger circle. These studies have summarized the changes occuring during the growth of the child. From three to five years of age, there is generally very little change in arch width ${ }^{4}$. It is usually not until the emergence of the lateral incisors that there is a large increase in intercanine width, tending to releive the crowding which may have resulted during the eruption of the centrals 29 . The increase usually holds from five to eight or nine years of age, and has been cited to vary from $2.8 \mathrm{~mm} .{ }^{22}$ to $3 \mathrm{~mm} .^{4}$ This stage has been regarded as the plateau of growth in intercanine width after which only very little expansion occurs 29,40 . During the eruption of the canines, there is only a $0.34 \mathrm{~mm}$. increase in width, with no subsequent changes expected ${ }^{22}$. Some authors however, have observed a slight decrease in width ranging from $0.5 \mathrm{~mm} .^{6}$ to $1.5 \mathrm{~mm} .^{4}$ from fourteen years onward. Overall the changes in intercanine distance have been found 22,40 to vary from $3 \mathrm{~mm}$. to $5 \mathrm{~mm}$. during the transition from primary to permanent dentition.

These are the limitations in arch width set forth by nature, which the orthodontist has tried to surpass in an attempt to accomodate aligned teeth in the arch. Several 
studies on stability have focused on this aspect, exploring the amount of expansion possible with no following relapse. Concerning studies on retention, Litowitz 26 studied in 1948, twenty orthodontically treated cases which "remained stable subsequent to removal of all retention". The arches displayed an increase in intercanine, interpremolar, and intermolar width during treatment varying from $1 \mathrm{~mm}$. to $10 \mathrm{~mm}$., after which some of it was lost even though it was not complete. There was much variability in the percentage of loss, however, a slight effective increase was retained, particularly in the premolars. He concluded there was a strong tendency for the teeth to return to their original positions within the jaws.

In 1952, Donall studied the stability of orthodontic treatment using a sample of twelve nonextraction and ten extraction cases, with the post-retention period varying from two to six years. He found there was a tendency of the lower canines to return toward their original width if it had been increased, and to remain static if it had not been violated. This applied both to the extraction and non-extraction cases alike. He concluded orthodontic cases, following treatment tend to seek stability, therefore, "teeth are still moving following the retention period until they settle into a balanced state." Walter ${ }^{45}$, in 1962 , studied a combined sample of fifty extraction and fifty non-extraction cases, he found 
most of the cases which had been expanded showed a tendency to contract after treatment. At the intercanine width $62 \%$ of the non-extraction cases had a net post-retention increase of $2 \mathrm{~mm}$, and the same percentage of extraction cases had a net increase of $1.4 \mathrm{~mm}$. At the molar level, $72 \%$ of the non-extraction cases, maintained an average postretention expansion of $1.8 \mathrm{~mm}$. post retention. From both studies he concluded it was incorrect to say that the dental arch cannot be permanently widened. However, the results indicated by his study are questionalbe since many of the final measurements were performed intraorally, leaving much room for inaccuracy.

Steadman ${ }^{41}$, in 1961, studied thirty-one cases at least one year out of retention. He reported premolar extractions decreased the mandibular intermolar widths but produced no discernable difference in intercanine widths. He concluded orthodontic treatment produces stable changes, only when the forces acting upon the teeth have changed, therefore supporting the repositioned teeth in their new positions.

Amott ${ }^{l}$, in 1962, studied fifty five non-extraction cases with a minimum of four years out of retention. They were grouped according to Angle's classification. The results indicated that in $79 \%$ of the cases where the mandibular intermolar width had been increased during treatment, there was a subsequent lingual relapse occurring 
post-retention. Twenty percent of the group lost all recorded expansion, but $75 \%$ maintained part of it. The first premolars (70\%) and the canines (76.3\%) also tended to move lingually post-retention. Some expansion of the intercanine width was maintained in $46 \%$ of the cases: 0.3 $\mathrm{mm}$. in Class $I$, and $0.1 \mathrm{~mm}$. in Class II, division 1 cases. However, this was statistically negligible except for class II, division 2 cases, where the net expansion of $0.5 \mathrm{~mm}$. was significant. Comparing his results to Moorrees' growth norms, he found the intermolar width of the patients tended to approximate after retention, that of a normal untreated dentition, while the intercanine width remained slightly greater. He concluded that teeth which are expanded to alleviate the crowded condition, exhibit a tendancy to return to the pretreatment dimension particularly at the intercanine level.

Arnold ${ }^{3}$, in 1963, used a sample of fifty cases ( 30 extraction and 20 non-extraction), with a minimum of five years post-retention to study the changes in intercanine and intermolar widths during and after orthodontic treatment. His results disclosed in $70 \%$ of the cases the pattern of intercanine width change is one of treatment increase and post-treatment decrease. The tendancy was to revert to the original dimension $51 \%$ of the time, with $81 \%$ of the cases reverting from +0.5 to $-0.5 \mathrm{~mm}$., regardless of the amount of expansion. Statistical analysis indicated extraction had no 
significant effect on the frequency or amount of the resultant intercanine widths. It did however, display a significant effect on decreasing the intermolar width. He concluded, whether premolars are removed or not, the anticipated degree of relapse of the mandibular anteriors is proportional to the amount of increase of the intercanine width during treatment.

Welch ${ }^{46}$, in 1965 , studied the stability of the interarch dimensions in width, resulting from distal movement of the canines and mesial movement of the molars into the premolar extraction space. He used a sample of fifty-five, all extraction cases which had denoted an increase in intercanine width during treatment. The minimum post-retention period was five years. His findings show the predominant pattern of the intercanine width is one of treatment increase and subsequent post-treatment decrease, with this occurring in $97 \%$ of the cases. Five years post-retention, $56 \%$ of the sample showed an effective gain in width. This ranged from $0.25 \mathrm{~mm}$. to $4.75 \mathrm{~mm}$.

The average effective gain was $0.52 \mathrm{~mm}$, and $77 \%$ of the treatment expansion of the intercanine width relapsed after retention.

He drew the following conclusions:

a) Treatment expansion of intercanine width cannot be successfully maintained in any manner.

b) The amount of distal movement of the canines 
into the premolar extraction space had no significant effect on the post-retention intercanine width.

c) The intermolar width exhibited a strong tendency toward decrease in premolar extraction cases following a five or more years post-retention period. However, there was no correlation between the mesial movement of the molars into the extraction space and the loss of intermolar width.

Bishara, Chadha, and Potter ${ }^{5}$, in 1973, collected thirty extraction cases with an average of 14.2 months post-retention period, to examine among other things, the stability of the intercanine width. They found that the mandibular intercanine width increased during treatment $0.77 \mathrm{~mm}$. , subsequently displaying a $71.4 \%$ post-retention relapse. The net increase amounted to $.22 \mathrm{~mm}$. which is clinically negligible.

Shapiro ${ }^{36}$, in 1974, confirmed in his study of 80 cases at least 10 years out of retention, the "inviolability" of the mandibular intercanine width. His results indicated a distinct trend toward decrease during the post-retention period regardless whether the intercanine width had been increased or decreased during treatment. His sample consisted of extraction, non-extraction, Class I and Class I cases. It showed a mean increase in intercanine width of 
$1.4 \mathrm{~mm}$. during treatment and then a successive mean decrease of $1.8 \mathrm{~mm}$. upon removal of all retainers, leaving a net change of $-0.4 \mathrm{~mm}$. There was a statistically significant maintenance of the intercanine width of $1 \mathrm{~mm}$. in the class II, division 2 cases. Concerning the intermolar width, he found that during treatment the non-extraction cases exhibited an increase while the extraction cases exhibited a decrease. During the post-retention period, the intermolar width decreased in all groups except in Class II, division 2. A net expansion of the intermolar width, of $1 \mathrm{~mm}$. was maintained in the non-extraction group.

Gardner and Chaconas ${ }^{14}$, in 1976, worked with a sample of 103 cases which were out of retention at least one year with a mean of 5.2 years. They measured interarch width at the level of the canines, first bicuspids, second bicuspids and first molars. They found in the nonextraction sample, a treatment increase of the intercanine width of $1.23 \mathrm{~mm}$., with a $58.5 \%$ post-retention relapse, leaving a net expansion of $0.51 \mathrm{~mm}$. The first premolar increased $2.86 \mathrm{~mm}$. during treatment with a $13 \%$ postretention relapse. The second premolar increased $1.8 \mathrm{~mm}$. during treatment, with a post-retention relapse of $31.5 \%$. The molar displayed an increase of $2.04 \mathrm{~mm}$. during treatment, with a $2.9 \%$ post-retetnion relapse which indicates a high stability of this dimension. In the extraction cases, the results for the intercanine width were 
very similar displaying a $58.8 \%$ relapse. The second premolar width decreased during treatment and continued to decrease after retention. The intermolar width decreased during treatment $1.46 \mathrm{~mm}$. with a post-retention change of $0.03 \mathrm{~mm}$. They concluded the canine has tendancy to return to its original position.

Gallerano ${ }^{13}$, in 1976 , investigated the results of orthodontic treatment in eighty-three cases which had been out of retention at least nine years and six months, his main concern being the relapse of the lower incisors. He supports the findings of previous investigations concluding the vast majority of cases did not maintain any treatment induced expansion of intercanine width and the ones that did, were not predictable. He also found that maintenance of the pretreatment intercanine distance does not guarantee stability of the post-treatment alignment of the mandibular incisors. In addition, decrease in intercanine width occurring during the retention period is not systematically related to increase in crowding during the same period. Sondhi ${ }^{39}$, in 1980 , collected and studied data from fifty-three extraction cases which were photographed and digitized, finding distal movement of the canines did not ensure a stable increase in intercanine width. There was no significant relationship between mesiodistal position of both canines and molars and their respective interarch dimensions. 
In reviewing the literature concerning the stability of expansion of the lower arch after orthodontic treatment there appears to be a general concensus as to the clinical observations. Studies $1,3,5,11,14,36,46$ show a tendancy for teeth to move to some degree after treatment, decreasing the arch width established during treatment. This is particularly obvious at the intercanine level, which is referred to as an "inalterable dimension"28,42. Although the findings indicating a trend in post-retention decrease are overall in agreement, the findings concerning the amount of these changes display some variation. This may possibly be attributed to the differing post-treatment time, sample distribution as to facial types, and sample size upon which the different studies were based. The literature has provided little guidance for predicting which cases could be expanded. However, there appears to be an agreement on the tendancy of Class II, division 2 cases to show a greater potential for retaining some increase in arch width ${ }^{1,36}$. Thus, it is feasible to wonder which characteristics if any, do the Class II, division 2 patients have in common which allows them to withstand and hold a greater expansion of the lower arch.

Howes ${ }^{19}$, in 1957, explored the possibility of dental arch expansion being greater in the wide face than in the narrow face. He inferred from the observation of 232 cases, that gaining space through expansion is not feasible 
in individuals with oversized anterior teeth, narrow coronal and basal arches, and small bi-zygomatic, bi-gonial measurements. The opposite characteristics, plus a good facial pattern would indicate a good potential for expansion. This possibility was examined in 1978 by schulhof et. al. 37 while attempting to derive useful norms for the cuspid, premolar, and molar widths, which would minimize the chance of post-treatment relapse. He reviewed two independent projects which provided the basis for his research.

The first study by Schuler, investigated the buccal expansion of molars and cuspids utilizing frontal headplates. His results indicated there are two significant variables that affect the stability of an increased molar dimension. Patients with a low "Lower Facial Height" in the initial lateral cephalogram, and a large "Molar to Jaw" relationship in the final frontal $x$-ray could tolerate a greater expansion of the molars.

The second study, by Lestrel derived a norm for the contact point between the cuspid and the first premolar which could be used as a treatment goal in order to minimize relapse. A prediction formula was composed which established a norm for the measurement at the distal of the mandibular cuspids. This was based on the patient's tooth size, mandibular width, mandibular plane angle, and facial angle. The formula illustrated that a patient with a 
brachyfacial pattern had a wider arch than a dolicofacial patient with the opposite characteristics.

Later, Schulhof 37 tested the prediction formula using forty-seven treated cases. He found cases treated to the pre-established norm were more stable, only $50 \%$ showing up to $1 \mathrm{~mm}$. of relapse. Those cases which had been over-expanded showed a greater degree of relapse, while those whose width was less than the norm tended to increase post-retention. He concluded that the theoretical norm was a reliable measurement and may be used as a goal in treatment planning.

The literature has shown the feasibility of gaining arch length through expansion of the dental units, especially mandibular canines to be minimal. It must be realized that stability of the orthodontic results should be considered during treatment. It is important that the occlusion established remain within the bounds of normal muscle balance and function. This may be influenced by the amount of apical base available, and the relationship of apical bases to one another. It is the latter that brings to mind the thought of combining rapid palatal expansion and lower arch expansion to achieve greater stability.

There has been a growing interest in recent years in the use of rapid mid-palatal expansion as a part of orthodontic therapy. According to $\mathrm{Haas}^{17}$, the clinical use of rapid maxillary expansion appliance was introduced by 
Angel in 1860. The procedure held an important note in the early orthodontic and rhinologic literature, and enjoyed a wave of popularity among both professions during the latter part of the 19th and early part of the 20th centuries. After this period, it fell into disuse in this country. European orthodontists however, continued the use of this procedure: Derichsweiler ${ }^{10}$, in 1953, described the separation of the maxillae based on eighty cases, Kerbs 25 in 1958, did a study with metalic implants, and Korkhaus 23,24 , who is responsible for re-introducing the procedure in this country.

It was the seminar given by Korkhaus in 1956, at the University of Illinois, which influenced Haas to perform his experiments and develop the basis for his treatment philosophy. In $1958^{16}$, he undertook the study of the palatal expansion procedure, using the pig as the experimental animal. From this research, he concluded a significant widening of the maxillary dental arch may be achieved by the procedure. Simultaneously, this would produce an increase in internasal capacity and a significant expansion of the mandibular dental arch in response to "altered natural forces."

In $1961^{16}$, he reported a clinical study conducted on ten patients, five males and five females ranging from eight to nineteen years of age. They underwent mid-palatal suture opening with the tissue borne appliance, without any 
treatment in the lower arch. His observations indicated an effective expansion with opening of the suture occurred, and the mandibular arch tended to follow the maxillary teeth by tipping laterally. All cases manifested an intermolar width increase ranging from $0.5 \mathrm{~mm}$. to $2 \mathrm{~mm}$. Regarding the intercanine width, five cases showed no change while four had increases of 0.5 to $1.5 \mathrm{~mm}$. and one case exhibited a loss $0.5 \mathrm{~mm}$.

Wert ${ }^{47}$, in 1977 , studied cephalometrically the average response to mid-palatal suture opening. He observed that from the beginning of treatment to the completion of suture opening there was an average mandibular intermolar increase of $0.5 \mathrm{~mm}$. By the time the appliance was removed there was scarcely a change in the younger individuals but there was an average increase of almost $1 \mathrm{~mm}$. in those over eighteen. At the completion of full orthodontic therapy, the mandibular intermolar width had decreased an average of $1.5 \mathrm{~mm}$. with the older patients showing a greater decrease than the younger ones. This was blamed by the author on continued conventional orthodontic therapy. All of the figures were significant at the .05 level. Gryson ${ }^{15}$, in 1977 , studied the changes in mandibular interdental distance resulting only from the effect of mid-palatal expansion, i.e. before banding of the lower arch. After the completion of active expansion and a three month retention period, the appliance was removed and 
the post-expansion models were made 14 days later. The results indicated that there was no correlation between change in the mandibular intercanine or intermolar distances with respect to the increase in their maxillary counterparts. The mean change in mandibular intercanine distance was slightly less than $0.2 \mathrm{~mm}$, which was not significantly different from zero at .05 level. He concluded the use of rapid maxillary expansion as a method of increasing lower arch length cannot be justified, at least in short term.

In a later study, in 1980 , Haas ${ }^{19}$ reported on the long term post-treatment evaluation of rapid palatal expansion. He included ten previously published cases which had been from 4.5 to 12 years out of lower retention. He expressed again his belief that dental expansion in the lower arch when used in conjunction with palatal expansion, is a successful and stable treatment when indicated. This is illustrated with examples from various cases, some of which achieved and maintained an expansion of 3 to $4 \mathrm{~mm}$. in the intercanine width and up to $6 \mathrm{~mm}$. in the intermolar width. He sustained mandibular intercanine width can be increased in the non-grower if the apical base of the maxillary complex is permanently widened.

From the cited literature $1,3,5,11,13,14,26$, $31,35,36,41,46$, it is well established that if the lower arch is expanded during treatment, it will display a certain 
degree of relapse, with a tendancy to return to its original dimension. However, there are some indications $16,17,19,47$, of the possibility of achieving a stable expansion of the lower arch subsequent to expansion of the midpalatal suture. The research concerning this field still remains inconclusive. Thus, additional information regarding this subject would be interesting and useful to the orthodontic profession. 
The material used for this study included the records of twenty-eight cases from the private practice of Dr. Andrew Haas of Cuyahoga Falls, ohio. The records consisted of the initial, post-treatment and post-retention study models, and the initial lateral cephalogram of each patient. All patients had undergone rapid maxillary expansion with a tissue borne appliance (See Figure 1), according to Haas' published technique 16,18 , with subsequent orthodontic treatment. The mean age of the entire group was twelve years, and seven months, ranging from 6.4 to 21.9 years.

For the study of the intercanine and intermolar changes in arch width, the sample was divided into two separate groups respectively. Cases which met both of the subsamples' requirements were included in both groups. The general criteria for selection were the following:

Availability of a full set of study models including initial, post-treatment, and post-retention casts. 
FIGURE 1

Illustration of the Palate Splitting Appliance.

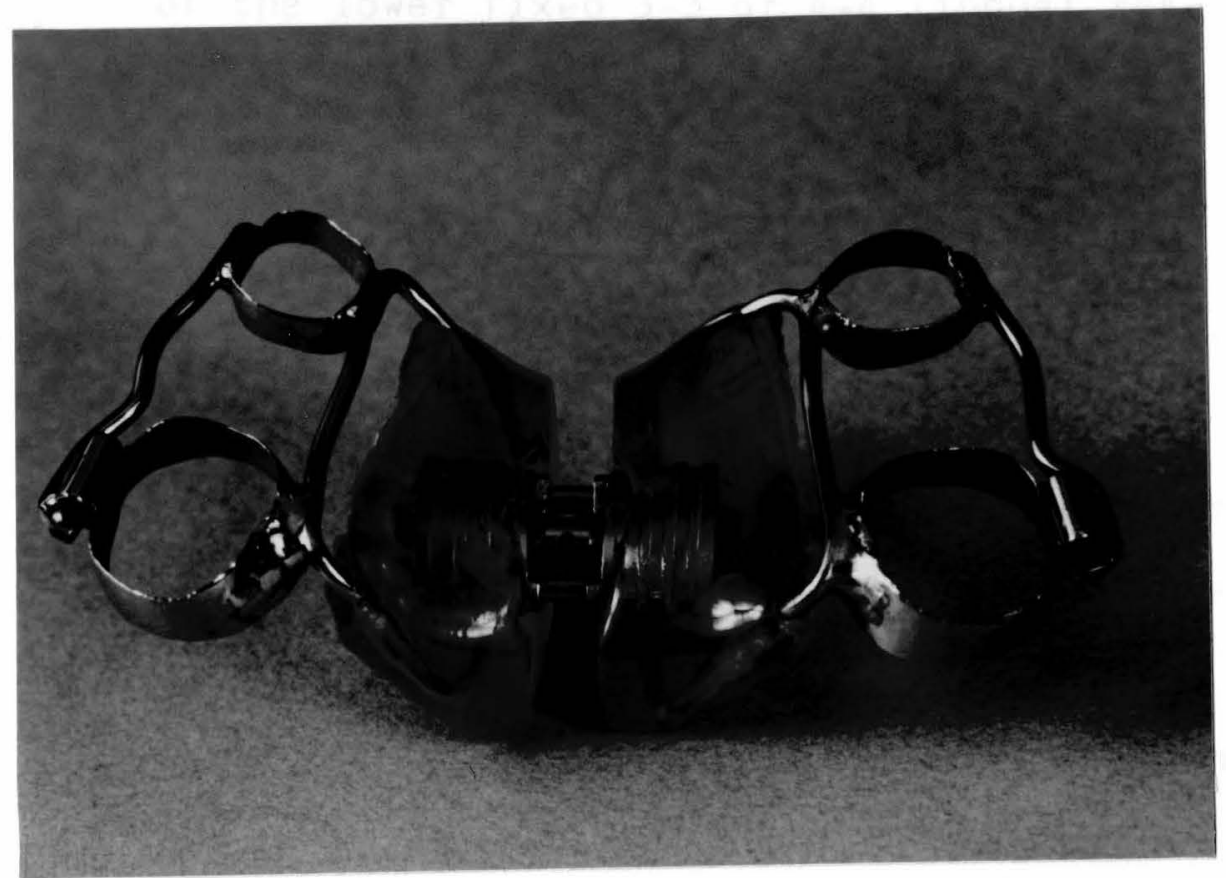

As described by Haas 16 , the palate splitting tissue borne appliance consists of four bands positioned on upper first molars and premolars, with connecting bars which are soldered to the buccal and Iingual surfaces of each pair of bands. The body consists of acrylic which covers the lingual bars, and encloses the expansion screw which lies directly over the midline, raised about $1 \mathrm{~mm}$. from the palate. 
2. For the study of the intercanine changes in arch width, availability of a set of post-retention dental casts taken at least two years after removal of the lower fixed $3-3$ or 4-4 lingual retainers was required.

3. For the study of the intermolar changes in arch width, availability of set of study models taken at least two years subsequent to the end of treatment was required.

4. Cases which displayed less than $1 \mathrm{~mm}$. of crowding in the initial models were disqualified for use in this study.

5. Cases with congenitally missing teeth in the mandibular arch were disqualified for use in this study.

The first group consisted of those cases meeting the necessary criteria for the study of the intercanine width. These were required to possess both permanent mandibular cuspids in the initial models, in addition to meeting the general criteria for selection. The group included seventeen cases, eight males, and nine females. The mean age at initiation of treatment was 14 , with a range of 9.6 to $\mathbf{1 9 . 6}$ years of age. After active treatment, a lower fixed lingual retainer was placed for an average period of five years and six months. The final models were taken at least two years with an average of five years and three months 
after the fixed retainer was removed.

The second group consisted of those cases for the study of the changes in intermolar width. Both the mesial and the distal intermolar widths were measured in order to determine if pure expansion or rotation had occurred. In addition to the general criteria for selection, the cases in this group were required to have a full compliment of teeth in the final casts, exclusive of third molars. The group consisted of twenty-two cases, eleven males and eleven females. The mean age at the onset of treatment was 12.6 years with a range of 6.4 to 21.9 years of age. All post-retention models were taken a minimum of two years with an average of eight years and eight months after the end of treatment. The description of the entire sample is displayed in Table I.

In order to accurately find the changes of the intercanine, mesial and distal intermolar widths, the following method was used to accurately reproduce the same landmarks for each of the three mandibular casts of one given case:

Each set of three study models pertaining to one patient were carefully studied and consecutively dotted with a $2 \mathrm{H}$ pencil. Three pairs of dots were marked in each lower study model. The first was selected at the tip of each mandibular permanent canine. The second and third dots were located on the first permanent molars. One was selected on 
TABLE I

Summary of Material

\begin{tabular}{|c|c|c|}
\hline $\begin{array}{l}\text { Total Number } \\
\text { of cases }=28\end{array}$ & Group A-Canines $N=17$ & Group B-Molars $N=22$ \\
\hline $\begin{array}{l}\text { Angle } \\
\text { Classification }\end{array}$ & $\begin{array}{l}\text { Class I-II } \\
\text { Class II, Div. I - } 3 \\
\text { Class II, Div. II - } \\
\text { Class III }-3\end{array}$ & $\begin{array}{l}\text { Class I- } 14 \\
\text { Class II, Div. I }-6 \\
\text { Class II, Div. II }-0 \\
\text { Class III - } 2\end{array}$ \\
\hline $\begin{array}{l}\text { Treatment } \\
\text { Procedure }\end{array}$ & $\begin{array}{l}\text { Extraction - } 3 \\
\text { Non-Extraction }-14\end{array}$ & $\begin{array}{l}\text { Extraction - } \\
\text { Non-Extraction }-22\end{array}$ \\
\hline$\overline{\operatorname{Sex}}$ & $\begin{array}{l}\text { Males - } \\
\text { Females }-9\end{array}$ & $\begin{array}{l}\text { Males - } 11 \\
\text { Females }-11\end{array}$ \\
\hline $\begin{array}{l}\text { Age at Initiation } \\
\text { of Treatment }\end{array}$ & $\begin{array}{l}\text { Mean - } 14 \text { yrs. } \\
\text { Range }-9.6 \text { to } 19.6 \text { yrs. }\end{array}$ & $\begin{array}{l}\text { Mean }-12.6 \text { yrs. } \\
\text { Range }-6.4 \text { to } 21.9 \text { yrs. }\end{array}$ \\
\hline Retention Time & $\begin{array}{l}\text { Mean }-5.6 \text { yrs* } \\
\text { Range }-2 \text { to } 8 \text { yrs. }\end{array}$ & $\begin{array}{l}-- \\
-\end{array}$ \\
\hline $\begin{array}{l}\text { Time out of } \\
\text { Retention }\end{array}$ & $\begin{array}{l}\text { Mean }-2 \text { yrs.* } \\
\text { Range }-2 \text { to } 11 \text { yrs. }\end{array}$ & $\begin{array}{l}- \\
-\end{array}$ \\
\hline $\begin{array}{l}\text { Time out of } \\
\text { Treatment }\end{array}$ & $\begin{array}{l}\text { Mean - } 10.8 \text { yrs. } \\
\text { Range }-7 \text { to } 15 \text { yrs. }\end{array}$ & $\begin{array}{l}\text { Mean }-8.8 \text { yrs. } \\
\text { Range }-2 \text { to } 14 \text { yrs. }\end{array}$ \\
\hline
\end{tabular}

* Two cases did not undergo treatment of the lower arch, and are therefore excluded when calculating means and ranges. 


\section{FIGURE 2}

Intra-arch distances measured in this study.

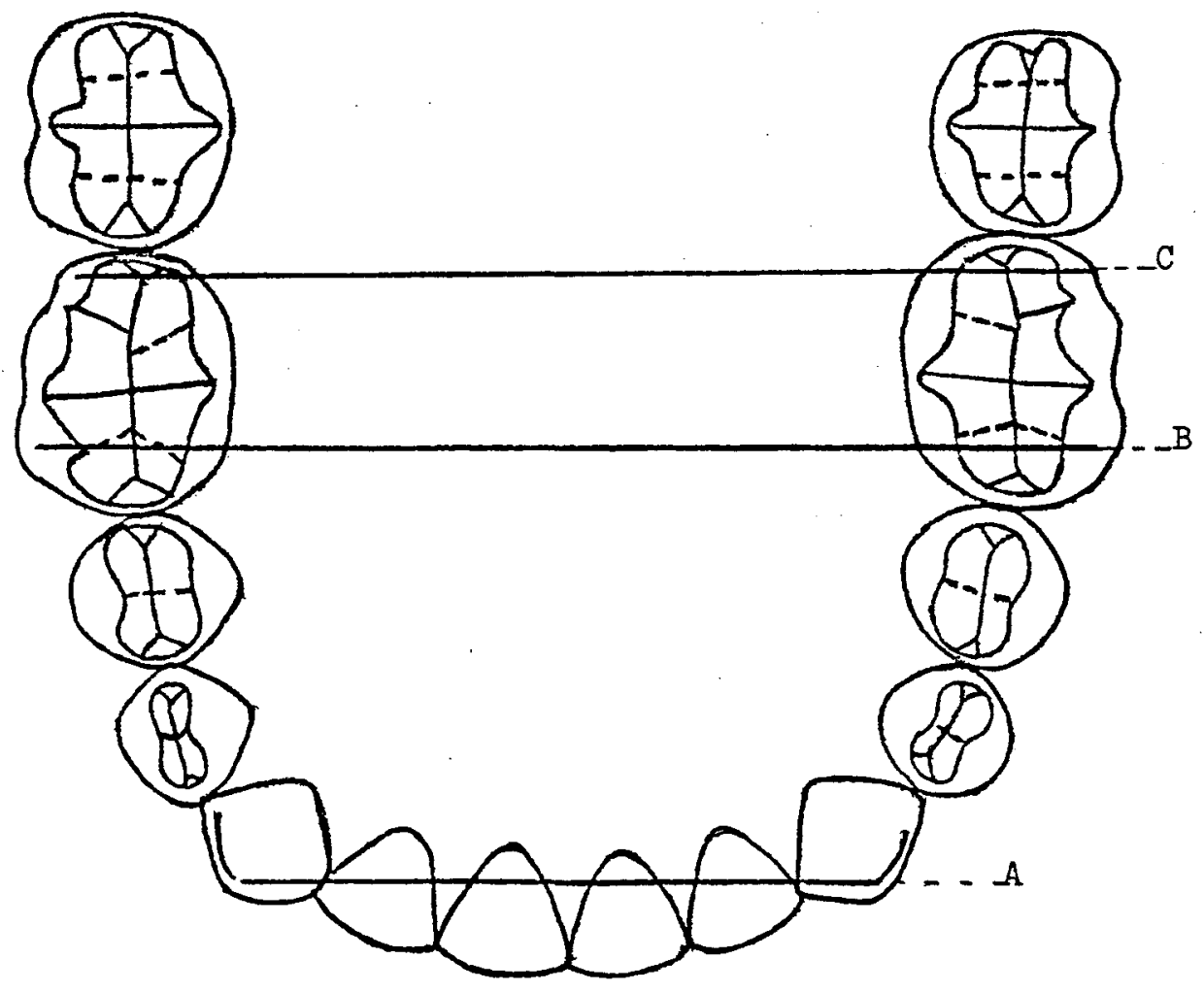

A: Intercanine distance

B: Mesial Intermolar distance

C: Distal Intermolar äistance 
the summit of the mesiolingual cusp and the other on the distolingual cusp respectively (Fig. 2).

Whenever possible, the above mentioned points were selected. However, when the teeth displayed extensive abrasion or restorations, other landmarks were used to select the most reproducible points. These included: the labial and lingual central ridges of the canines, and the grooves and fissures in the first molars. The same point on one tooth was located in all three casts before proceeding to the next landmark.

After the mandibular cast was marked, it was placed on the base of a surveyor. The dots were recorded with a two dimensional digitizer, connected to a 360 IBM computer, in order to determine the interdental measurements and changes in distance. The base of the surveyor was oriented and fixed when the pair of dots on the model to be measured were located parallel to the plane of movement of the pin on the digitizer. This was determined when both of the points were equidistant to the pointer of the digitizer (Figure 3). Measurements were recorded to the nearest $0.01 \mathrm{~mm}$.

To verify the accuracy in transferring the points from one cast to another, and of the method in general, all dimensions were measured independently by two individuals. A two sample $t$ test was run between all the measurements of the changes in width of the intercanine and the intermolar distances as measured by one observer, against the same 
FIGURE 3

Illustration of digitizer set-up.

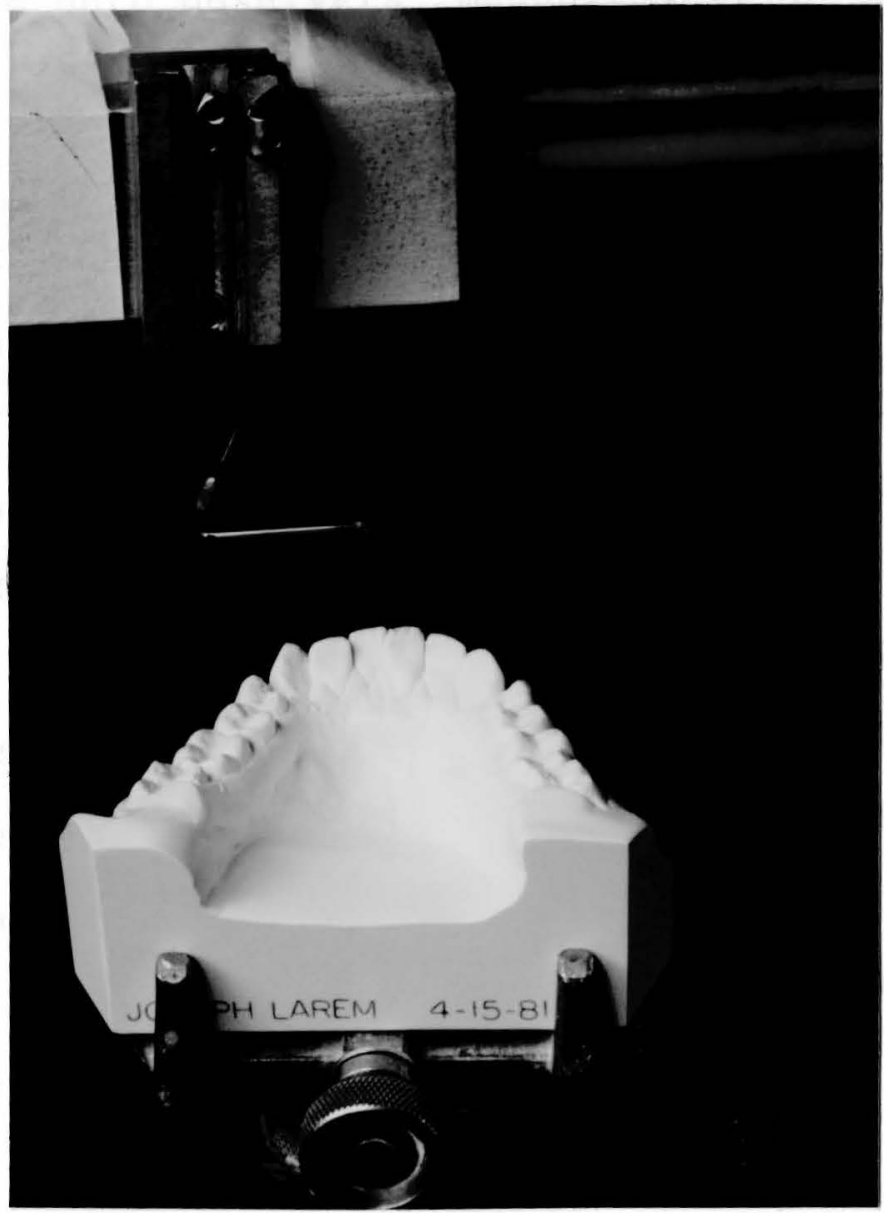


changes in distance as measured by the other observer. This was done in order to test the significance of the difference between both observers' measurements of these changes.

In order to test the significance of the change between the initial versus the final, the final versus the post-retention, and the initial versus the post-retention casts, a paired t test was employed. This was done twice for the results of the two investigators independently to verify if both of their measurements were in agreement and led to the same conclusions.

In order to evaluate if the mesial points of the molars were significantly more expanded than the distal points, a two sample $t$ test was run between the change from the initial to the post-retention mesial intermolar width and the change from the initial to the post-retention distal intermolar width.

The changes in intercanine and intermolar widths is presented in the four quadrant $X-Y$ axis system as first used by Arnold in 1963 and welch in 1965. They reasoned that because only three possible treatment changes exist, i.e. increase, decrease, or maintenance of the pre-treatment dimension and since the same three possibilities apply to the post-treatment changes, the four quadrant system would adequately present the data. It displays graphically, the patterns of change, their frequency and their quantitative interpretation in a simple and rapid manner. 
The data was plotted on the four quadrant graph as follows: (See Figure 4) The $x$ or horizontal axis is the treatment axis. The $Y$ or vertical axis is the posttreatment axis. Any change during treatment or posttreatment (whether it be increase, decrease, or maintenance of a given dimension), may be quantitatively shown along the $X$ and $Y$ axis respectively. For instance, any case below the $x$ axis indicates a decrease in post-treatment dimension, above the $x$ axis a post-treatment increase in dimension. Any case to the right of the $Y$ axis indicates a treatment increase in dimension, to the left of the $Y$ axis a decrease in treatment dimension.

It is easily seen that by plotting the treatment change versus the post-treatment change for each case, the patterns of change and their frequency for the entire sample are graphically displayed. For example, in Figure 4, any case falling in quadrant I, would indicate a pattern of increase during treatment, with a subsequent increase following treatment. The number of cases in this section would indicate the frequency of this pattern. The same applies to the other quadrants.

In order to determine if there is a singificant relationship between the facial types of the sample at initiation of treatment, and the amount of interarch expansion retained post-retention, the lateral cephalograms were analyzed and the members of the sample classified into 
Explanation of the Four Quadrant Graph.

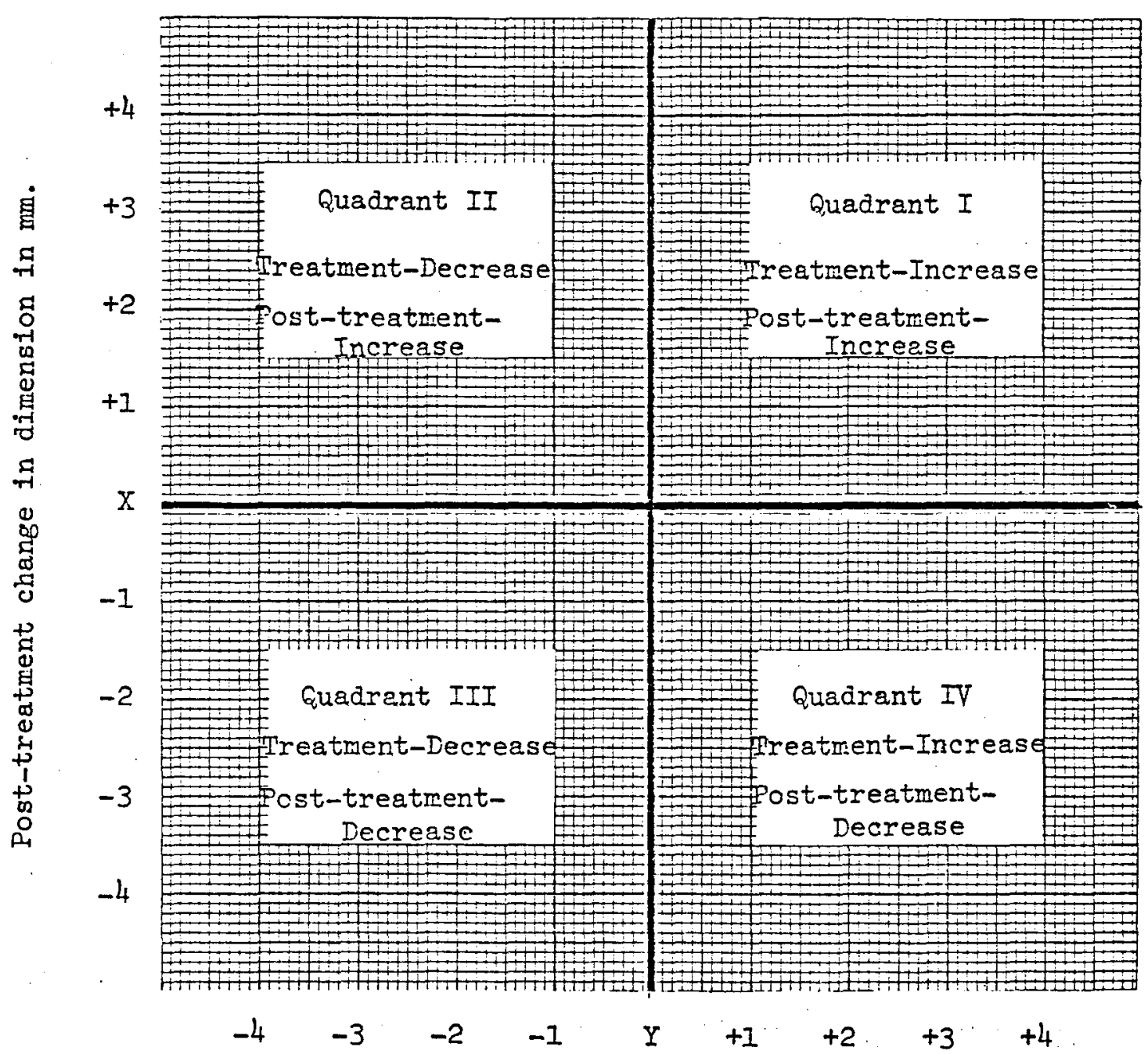

Treatment change in dimension in m. 
facial types, according to Ricketts ${ }^{33}$. Each $x$-ray was traced, and the landmarks shown in Figure 5 were located. The planes necessary to constitute the following angles were traced, and the angles measured for each patient (Figure 6): 1. Facial Axis - angle between Facial Axis and Na-Ba. 2. Facial Angle - angle between Facial Plane and Frankfurt Plane.

3. Mandibular Plane Angle - angle between Mandibular Plane and Frankfurt Horizontal.

4. Lower Facial Height - angle from ANS-XI-Po. 5. Mandibular Arc - angle between Corpus and Condylar Axis.

The facial type index was calculated to derive a single value which would describe the degree to which each patient's face is a vertical or horizontal pattern. It was calculated with the formula described by christie ${ }^{9}$, and the five measurements used by Ricketts 34 , to describe facial types, as follows (Table II):

For each measurement, the $z$ score or the amount of clinical deviations from the norm, according to sex and age, was determined with the following formula:

Clinical Deviation from norm $=\frac{\text { Measured Value }- \text { Norm }}{\text { Clinical Deviation }}$ This value expresses in units of variation the extent of dysplasia between the measured value and the norm ${ }^{34}$. The clinical deviation for the five measurements 
FIGURE 5

Series of lanomarks located on lateral cephalogram.

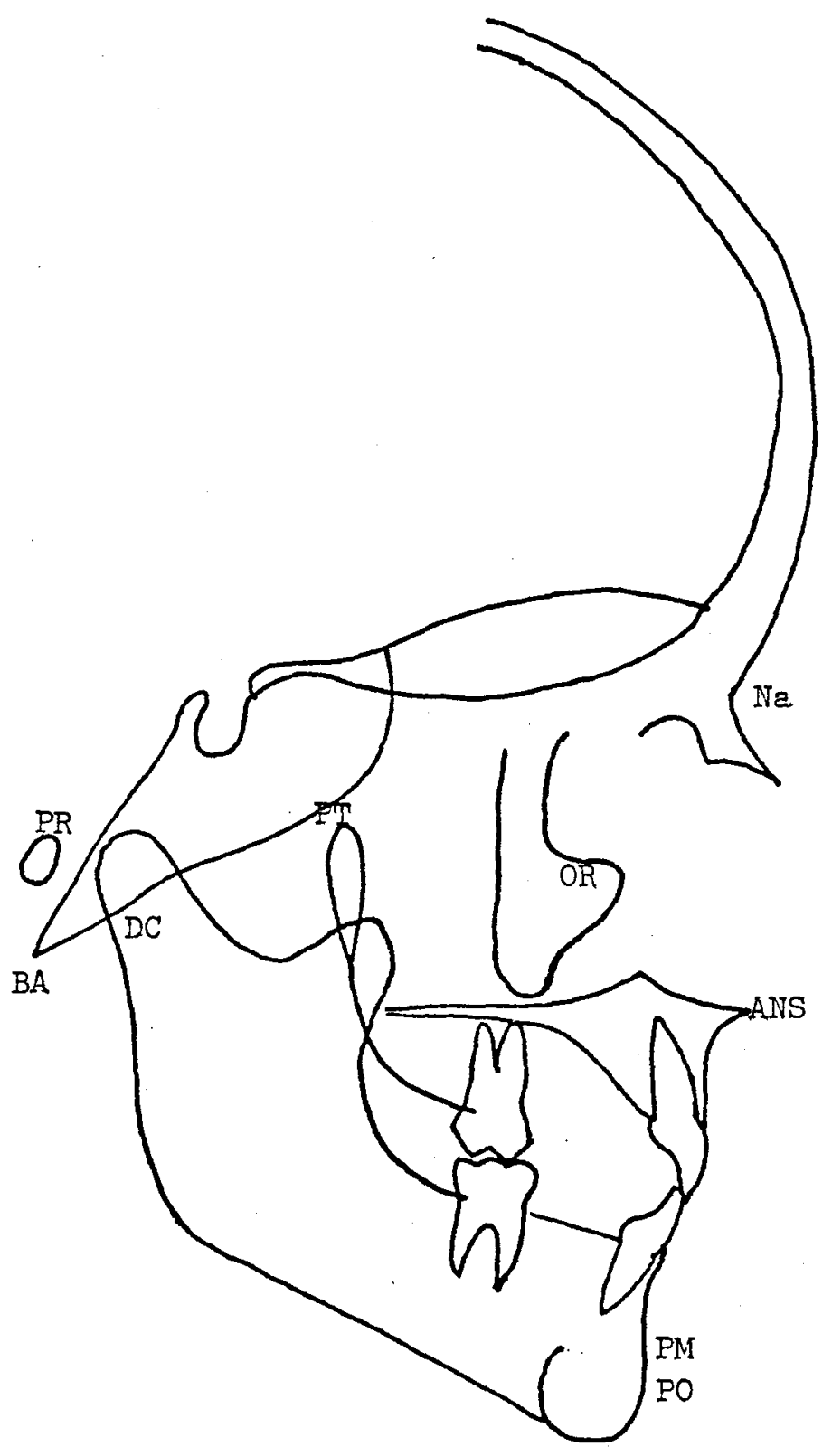




\section{FIGURE 6}

Series of angles measured on lateral cephalogram.

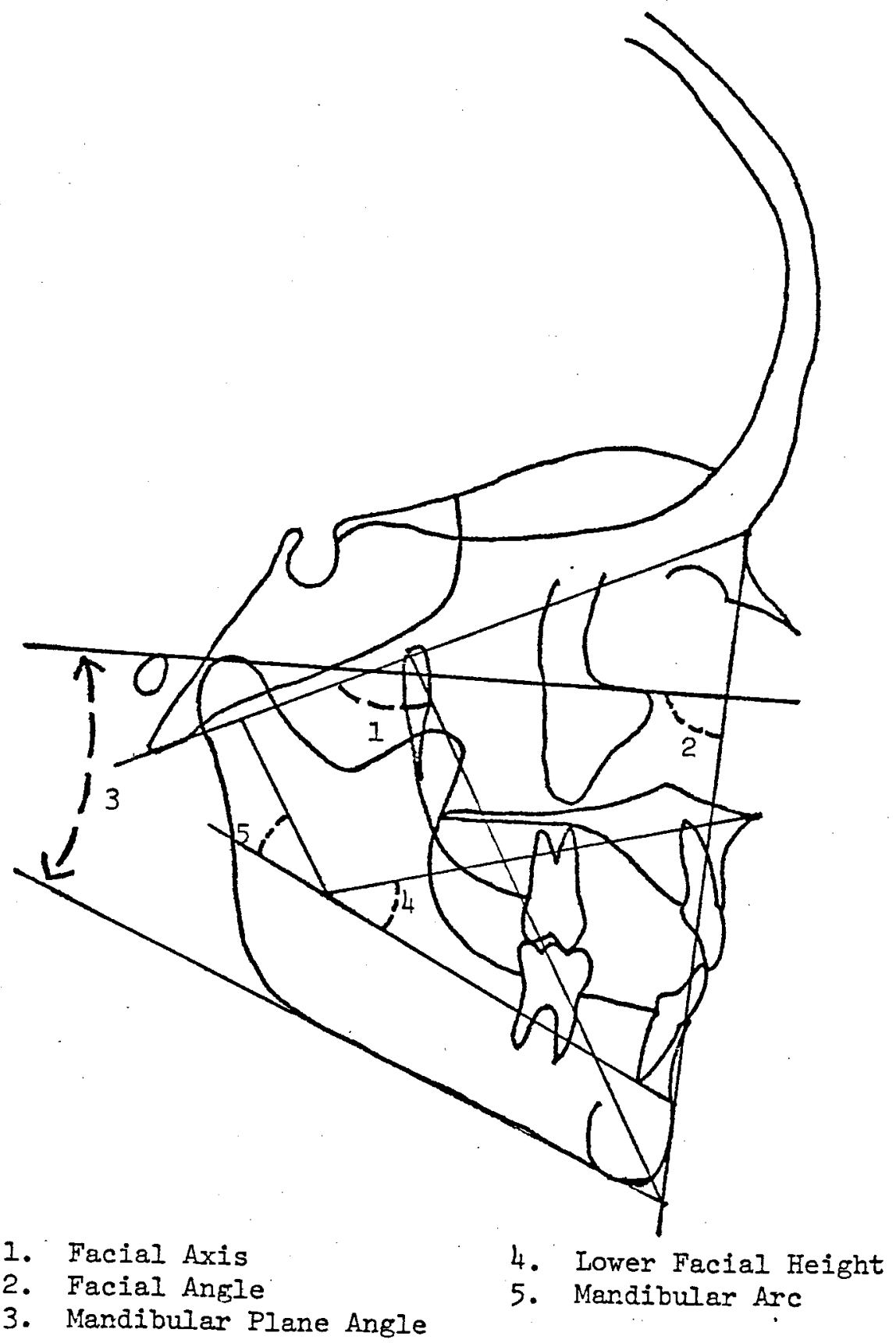


TABLE II

Calculation of Facial Type Index

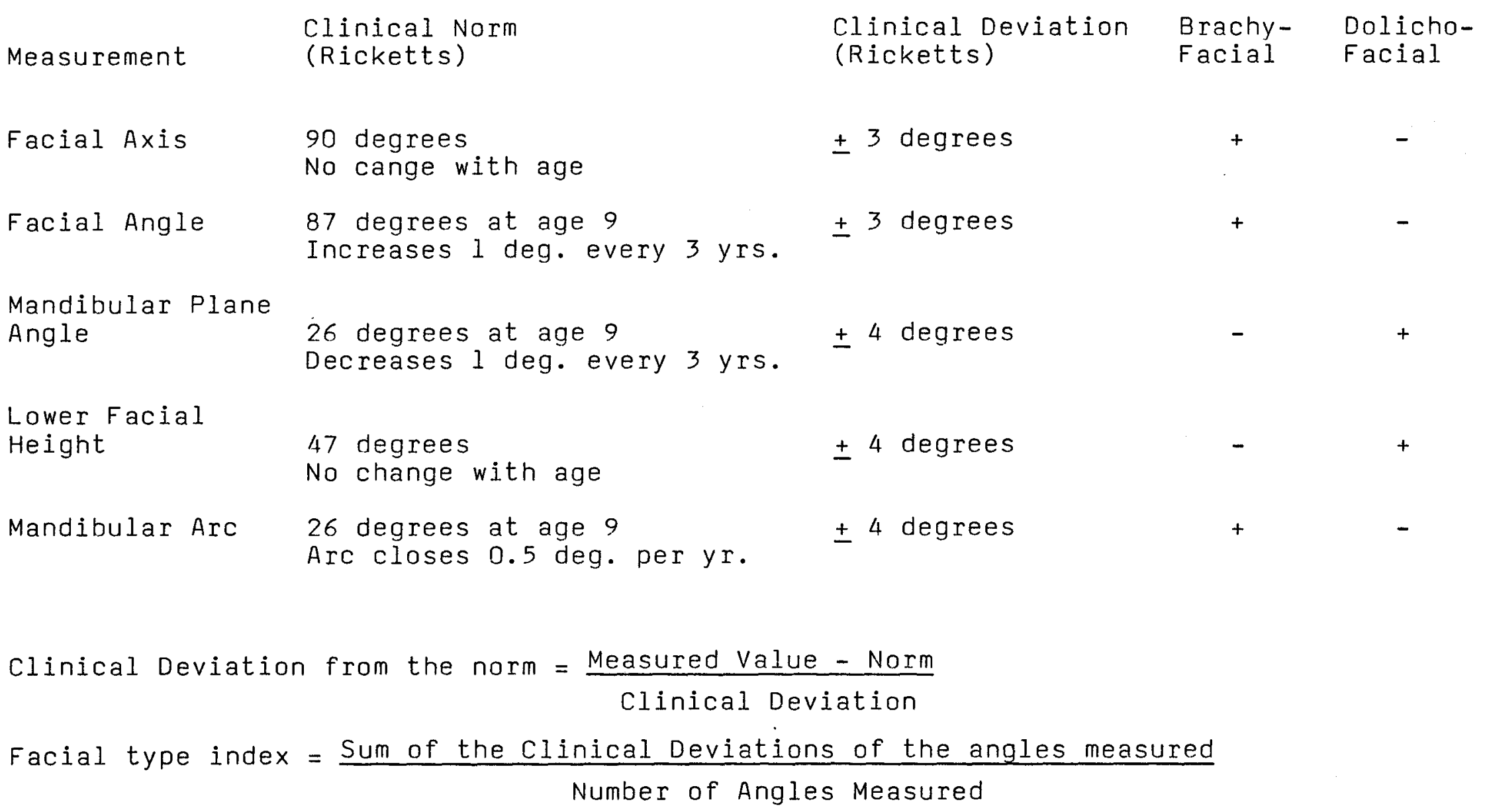


were added and averaged with the proper sign to calculate the facial type index. A positive result above +1 indicated a brachyfacial pattern, and a negative result below - 1 showed a dolichofacial pattern. Any case falling between +1 and -1 indicated a mesofacial pattern.

In order to graphically depict the frequency distribution of these results, a histogram was employed to plot the facial types.

The facial types according to the initial lateral $x$-ray were correlated against the change in intercanine and intermolar width shown from the initial to the post-retention casts, and a $t$ test was run, in order to confirm if there is a significant relationship between these two factors.

The age of the sample at initiation of treatment was correlated against the change in intercanine and intermolar width shown from the initial to the post-retention casts, and a t test was run, in order to confirm if there is a significant relationship between these two factors. 


\section{FINDINGS}

The raw data upon which this study is based is presented in Tables I through III in the Appendix. They include the "Treatment", "Post-treatment", and the "Resultant changes" in mandibular intercanine, mesial and distal intermolar dimensions. The "Treatment change," represents the changes displayed from the pre-treatment to the post-treatment study models. The "Post-treatment change," is the alteration in width exhibited from the post-treatment to the post-retention casts. The "Resultant change," represents the net change between the pre-treatment and the post-retentions casts. Any increase in dimension results in a positive quantity. Conversely, any decrease in width results in a negative quantity.

These tables are subdivided into part $A$ and $B$ in order to present separately the data collected by each of the two observers $A$ and $B$ respectively. Tables $I-A$ and $I-B$ in the Appendix, display the "Treatment", "Post-treatment", and "Resultant changes" in width for the canines. The results concerning the mesial landmarks of the first molars 
are presented in Tables II-A and II-B in the Appendix. The results regarding the distal landmarks of the first molars are presented in Tables III-A and III-B in the Appendix.

To verify the reliability of the method, a two sample $t$ test was done to find if there was a significant difference between the values of the "Treatment", "Post-treatment", and "Post-retention changes" as measured separately by each of the two observers. The resultant $t$ value was -0.30 , indicating that there is no significant difference between observers at $P=0.01$.

Table III is a tabulation of the means and standard deviations of the "Treatment", "Post-treatment" and "Resultant changes" of the intercanine, mesial, and distal intermolar widths. It shows an increase in width from the beginning to the end of treatment followed by a subsequent decrease, with the canines displaying a greater post-treatment decrease than the molars.

Table IV shows the significance of the changes in canine, mesial, and distal molar widths which occurred during each time interval studied, i.e. "Treatment change", "Post-treatment change" and "Resultant change". The $t$ values and their level of significance are displayed for each observer in this table. It indicates the following: 1. "Treatment change": This was significantly greater than zero for the intercanine, mesial and distal intermolar widths, at $P=.0005$. 
Summary of the means of "Treatment", "Post-treatment" and "Resultant changes".

\begin{tabular}{|c|c|c|c|c|c|c|c|}
\hline \multirow[t]{2}{*}{ Dimension } & \multirow[t]{2}{*}{ Observer } & \multirow{2}{*}{$\begin{array}{c}\text { Treatment } \\
\text { Mean } \\
\mathrm{mm} .\end{array}$} & \multirow{2}{*}{$\begin{array}{c}\text { Change } \\
\text { S.D. } \\
\text { mm. }\end{array}$} & \multicolumn{2}{|c|}{ Post-Treatment Change } & \multirow{2}{*}{$\begin{array}{c}\text { Resultant } \\
\text { Mean } \\
\text { mm. }\end{array}$} & \multirow{2}{*}{$\begin{array}{l}\text { Change } \\
\text { S.D. } \\
\mathrm{mm} \text {. }\end{array}$} \\
\hline & & & & $\begin{array}{l}\text { Mean } \\
\mathrm{mm} \text {. }\end{array}$ & $\begin{array}{l}\text { S.D. } \\
\mathrm{mm} .\end{array}$ & & \\
\hline \multirow{2}{*}{ Canines } & A & 2.11 & 1.29 & -1 & .82 & 1.11 & 1.52 \\
\hline & $\mathrm{B}$ & 2.26 & 1.43 & -1.09 & 1.30 & 1.17 & 1.64 \\
\hline \multirow{2}{*}{ Mesial Molars } & $A$ & 3.16 & 1.99 & -0.38 & 1.77 & 2.78 & 2.21 \\
\hline & B & 3.39 & 2.05 & -0.66 & 1.67 & 2.75 & 2.50 \\
\hline \multirow{2}{*}{ Distal Molars } & $A$ & 2.72 & 2.11 & -0.22 & 1.98 & 2.49 & 2.47 \\
\hline & B & 2.97 & 2.02 & -0.42 & 2.10 & 2.56 & 2.59 \\
\hline
\end{tabular}

$A=$ Changes as measured by observer $A$.

$B=$ Changes as measured by observer $B$. 
TABLE IV

Summary of Paired t tests of the "Treatment", "Post-treatment" and "Resultant changes" in dimension.

Pre-Treatment vs. Post-Treatment $=$ Treatment Change

Dimension

Canine

Mesial Molar

Distal Molar
Observer

$\begin{array}{ll}A & 6.74 \\ B & 6.52 \\ A & 7.45 \\ B & 7.76 \\ A & 6.05 \\ B & 6.90\end{array}$

$P$

$\begin{array}{ll}P & .0005 \\ P & .0005 \\ P & .0005 \\ P & .0005 \\ P & .0005 \\ P & .0005\end{array}$

Post-Treatment vs. Post-Retention = Post-Treatment Change

Dimension

Canine

Mesial Molar

Distal Molar
Observer

$\begin{array}{llll}A & -5.02 & P & .005 \\ B & -3.46 & P & .005 \\ A & -1.01 & P & .05^{*} \\ \text { B } & -1.85 & P & .05^{*} \\ A & -0.42 & P & .05^{*} \\ B & -0.99 & P & .05^{*}\end{array}$

Pre-Treatment vs. Post-Retention = Resultant Change

Dimension

Canine

Mesial Molar

Distal Molar
Observer

$\begin{array}{ll}A & 3.01 \\ B & 2.94 \\ A & 5.90 \\ B & 5.61 \\ A & 4.73 \\ B & 4.64\end{array}$

$P \quad .005$

$P \quad .005$

$P \quad .0005$

$P \quad .0005$

$P \quad .0005$

$P \quad .0005$

* = Values not statistically significant. 
2. "Post-treatment change": a) There is a decrease in intercanine width significantly less than zero at $P=0.05$. b) The intermolar width also decreased, but was not significant at $P=0.025$.

3. "Resultant change": This value was significantly greater than zero at $P=0.005$ for the canines, and at $P=0.0005$ for the molars.

The results of the paired t tests were consistent for both observers in all cases, indicating that the results attained with this method of evaluation are independent of the observer.

Table $V$ displays an average of the data of observers $A$ and $B$. It includes the means and ranges for the intercanine, mesial and distal intermolars widths for the "Treatment", "Post-treatment" and "Resultant changes".

Figure 7 illustrates the average amount of treatment increase and post-treatment decrease for the canines, mesial and distal points for the molars separately. Time intervals are represented in the $Y$ axis, being divided into three stages: "Before-treatment", "Post-treatment" and "Post-retention". The $x$ axis represents the changes in distance in $\mathrm{mm}$. It may be noted that the molars exhibit a steep increase in dimension with a slight decrease post-retention. The canines show a smaller amount of increase with nearly $50 \%$ of this declining subsequently. 
TABLE $V$

Average between the data of observers $A$ and $B$.

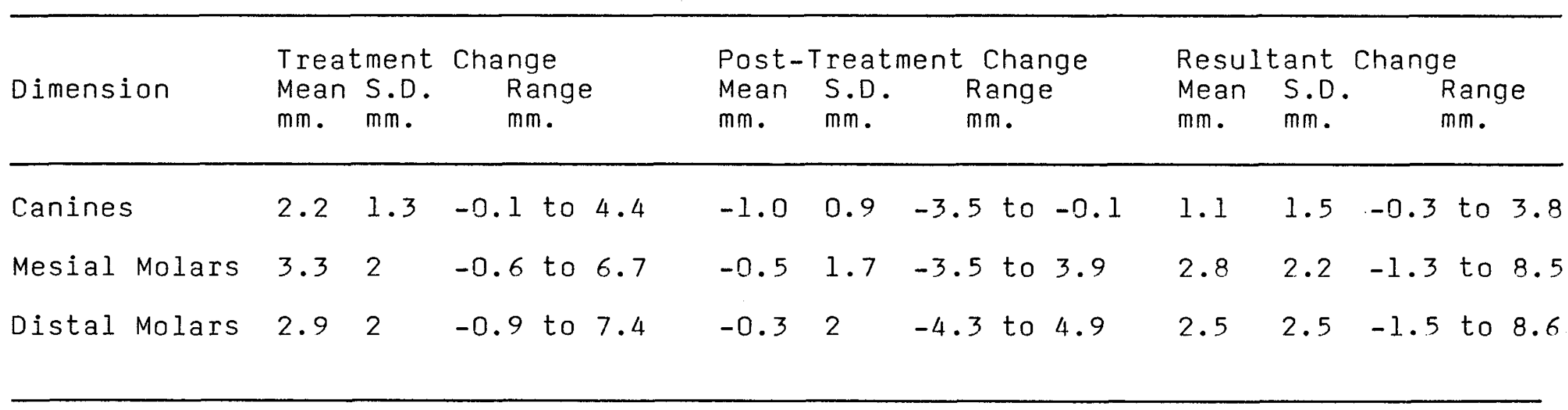


FIGURE 7

Diagram of the change in $\mathrm{mm}$. from the Initial to the Post-treatment, to the Post-retention width, for the intercanine, mesial and distal intermolar dimensions.

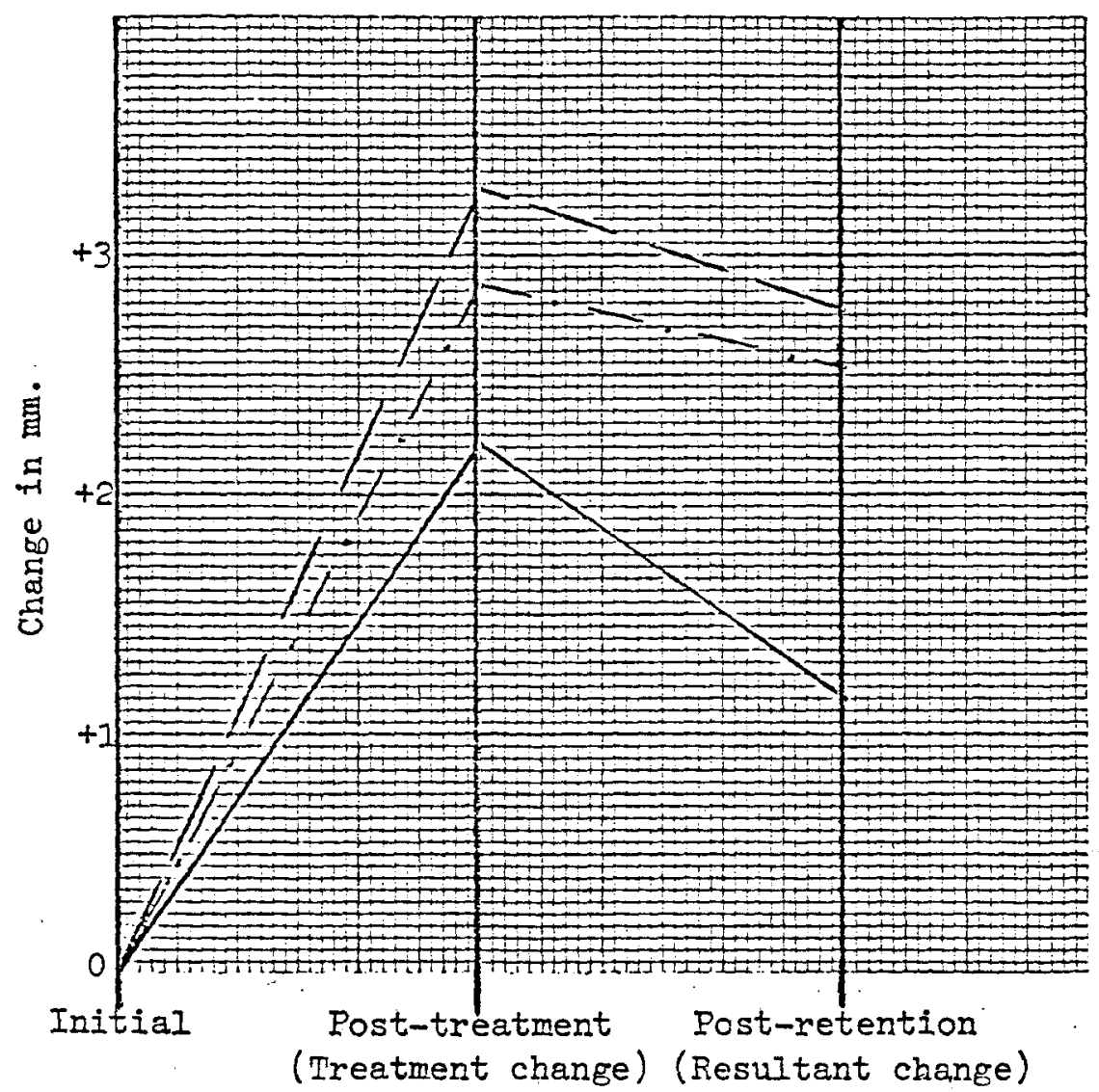

: Intercanine width

Post-treatment change $=2.19 \mathrm{~mm} . \pm 1.3 \mathrm{~mm}$. Resultant change $=1.14 \mathrm{~mm} . \pm 1.5 \mathrm{~mm}$.

----: Mesial Intermolar width

Post-treatment change $=3.28 \mathrm{~mm} . \pm 2 \mathrm{~mm}$.

Resultant change $=2.77 \mathrm{~mm} . \pm 2.2 \mathrm{~mm}$.

Distal Intermolar width

Post-treatment change $=2.88 \mathrm{~mm} . \pm 2 \mathrm{~mm}$.

Resultant change $=2.48 \mathrm{~mm} . \pm 2.5 \mathrm{~mm}$. 
INTERCANINE WIDTHS

The data of the changes in width during treatment and the subsequent changes post-treatment for the total sample are plotted in Figure 8 . To graphically display the data, it is plotted in the four quadrant $X-Y$ axis system with the $x$ or horizontal axis indicating the treament axis and $Y$ or vertical axis indicating the post-treatment axis (for explanation see Materials and Method).

In analyzing the treatment pattern, it can be noted that sixteen out of seventeen or $94 \%$ of the cases fall to the right of the $Y$ axis. This indicates that an increase of intercanine width during treatment is the predominant occurence. The other case, displays a $0.1 \mathrm{~mm}$. decrease during treatment.

Concerning the post-treatment pattern, it is interesting to note that not one single case is plotted on or above the $x$ axis. This indicates that following treatment, all cases exhibited a decrease in intercanine width.

In order to relate the treatment increase of the intercanine width, versus the post-treatment decrease, the sixteen cases which exhibited an increase during treatment are plotted in Figure 9. This figure is a reproduction of quadrant four in Figure 8 , including only the cases which displayed a treatment increase followed by a subsequent decrease. The $Y$ axis represents the increase during 
FIGURE 8

Treatment change and Post-treatment change in intercanine wiath of 17 cases.

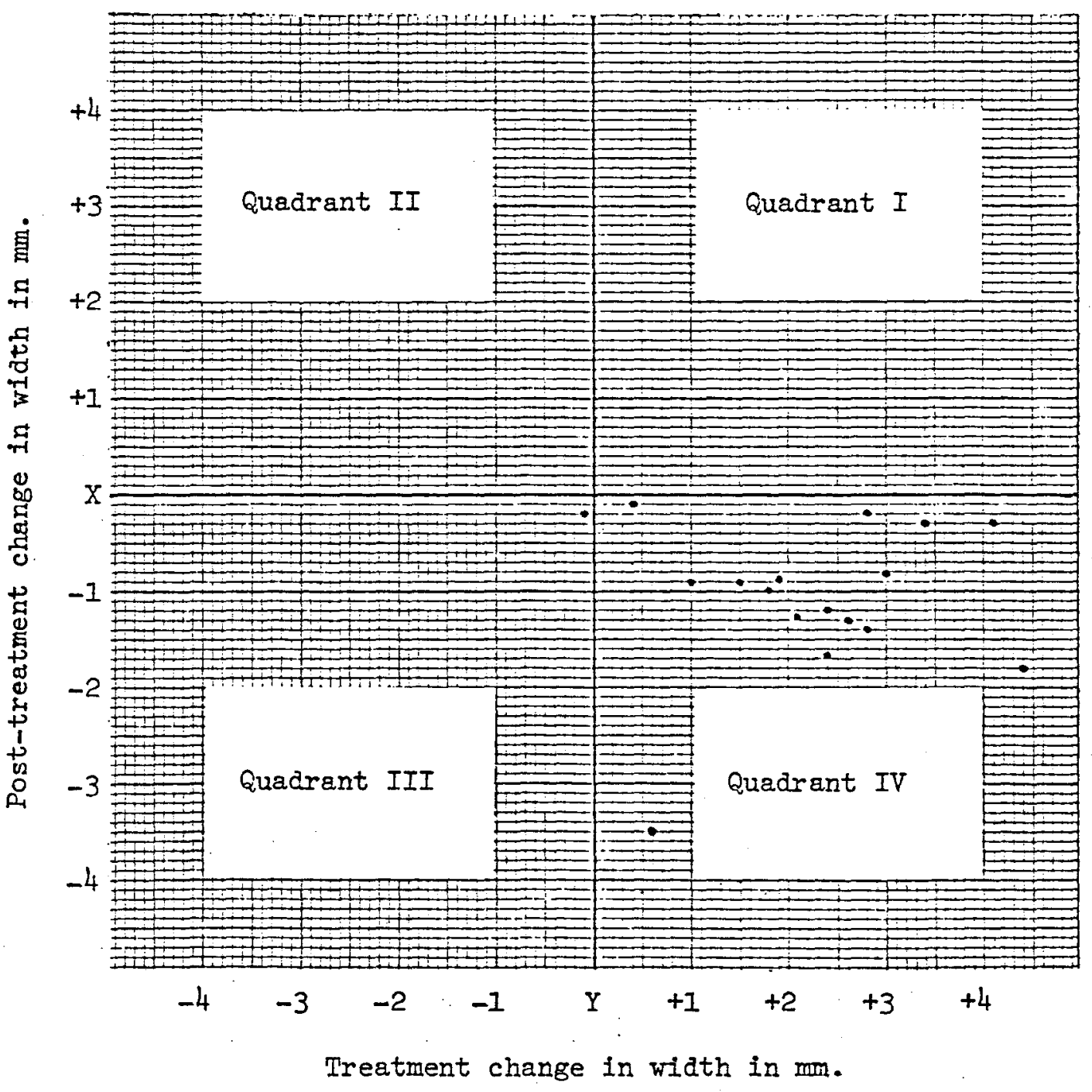


FIGURE 9

Resultant intercanine width following treatment increase of the original intercanine wiath.

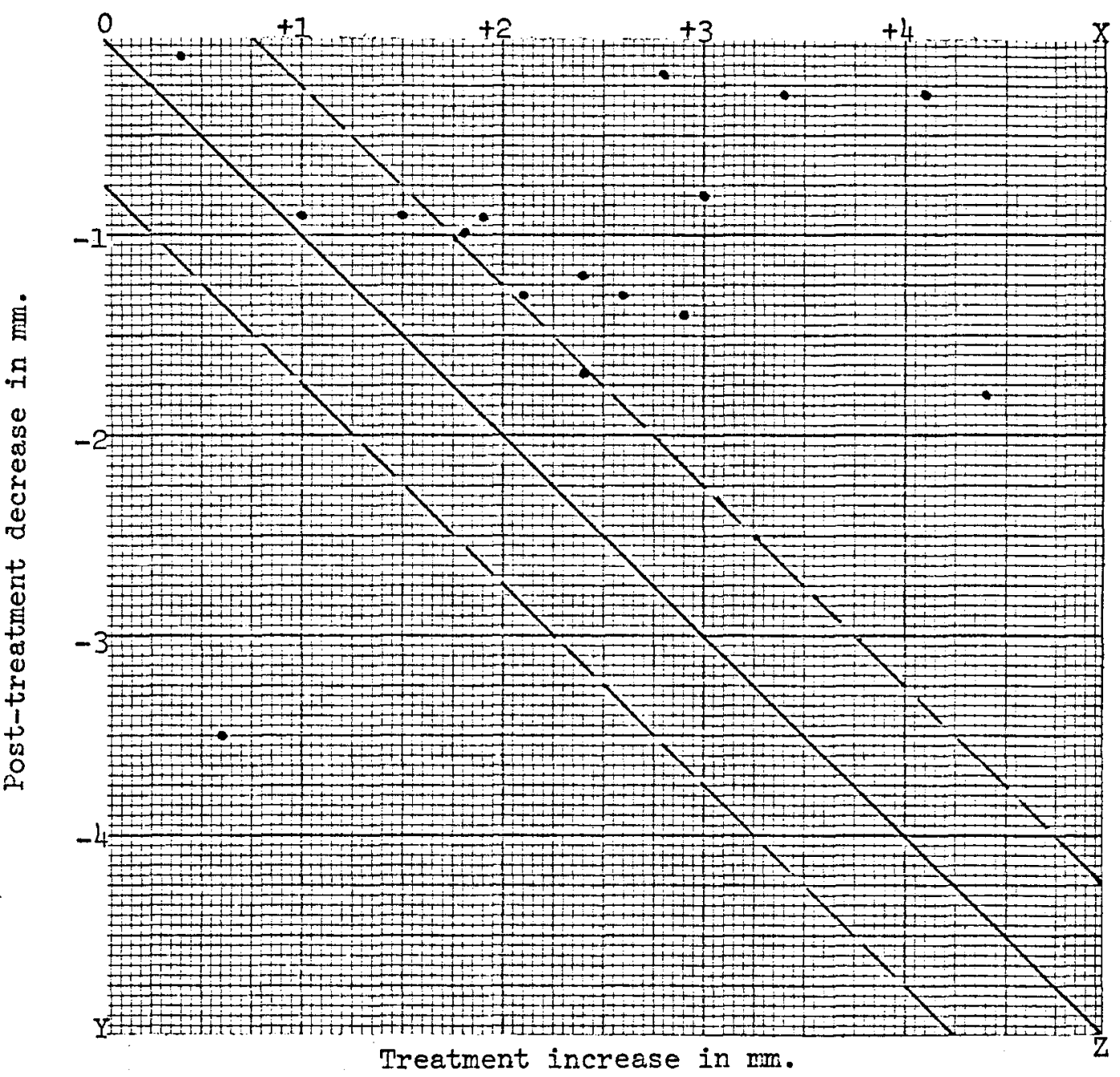

$\mathrm{Cn} \mathrm{Z}$ axis - Original and Post-retention intercanine wiaths the same.

Below $\mathrm{Z}$ axis - Net decrease in vidth.

Above $Z$ axis - Net increase in width. 
treatment and the $x$ axis represents the post-treatment decrease. In addition, a $z$ axis with a slope of -1 and a $Y$ intercept of zero is used in this graph. This axis allows rapid interpretation of the resultant intercanine widths. Any case falling on the $z$ axis indicates that the amount of increase during treatment is equal to the amount of decrease following retention. Any case falling above the $Z$ axis indicates a net gain in intercanine width, and conversely any case displayed below the $Z$ axis indicates a net loss in width. Two dashed lines indicating a deviation of +0.75 and -0.75 from the $Z$ axis have been added to the graph.

The following observations are made concerning the frequency of the "Resultant changes" in intercanine widths of the sixteen cases in which the effect of treatment was to increase the original intercanine dimension:

1. Forty-eight percent of the total expansion gained during treatment, was lost after the retention period, while $52 \%$ of the total expansion was retained.

2. Fifteen cases or $94 \%$ show an effective or net gain in intercanine width ranging from $0.1 \mathrm{~mm}$ to $04.4 \mathrm{~mm}$. (above the $z$ axis). They may be analyzed as follows:

a) Four cases or $25 \%$ revert to within $0.75 \mathrm{~mm}$. of the original dimension.

b) Thirteen cases or $81 \%$ had an increase greater than $0.5 \mathrm{~mm}$. 
c) Eleven cases or $69 \%$ had an increase greater than $0.75 \mathrm{~mm}$.

d) Eight cases or $50 \%$ had an increase greater than $1.0 \mathrm{~mm}$.

3. Only one case shows an effective loss in intercanine width of $2.9 \mathrm{~mm}$. (below the $Z$ axis).

4. None of the cases assume the intercanine width of the original malocclusion (on the $z$ axis).

\section{INTERMOLAR WIDTHS}

Table VI displays the results of the two sample $t$ test which was performed between the means of the resultant changes of the mesial and distal points on the molars. They indicate that the amount of "Resultant" expansion displayed by the mesial points as compared to the distal points is not significantly different than zero at $P=0.10$, demonstrating that the molars had been evenly expanded rather than rotated. Nevertheless, both measurements are plotted separately in order to analyze individual variations in the frequency of the patterns.

The data of the "Treatment" and "Post-treatment changes" are shown in Figure 10 and Figure 11 for the mesial and distal intermolar widths respectively. These graphs are similar to Figure 8 with the exception that a $Z$ axis has been added. Any case above the $z$ axis indicates a net gain in width, and any case below the $z$ axis indicates a net loss of the mesial or distal intermolar widths. 
TABLE VI

Summary of the two sample $t$ tests of the "Resultant changes" between the mesial and distal intermolar widths.

Dimension Observer Mean S.D. $t$ P

\begin{tabular}{|c|c|c|c|c|c|c|}
\hline Mesial & A & 2.78 & 2.49 & \multirow{2}{*}{.41} & \multirow{2}{*}{$P$} & \multirow{2}{*}{$.10^{*}$} \\
\hline Distal & A & 2.49 & 2.47 & & & \\
\hline Mesial & $B$ & 2.75 & 2.56 & \multirow{2}{*}{.26} & \multirow{2}{*}{$P$} & \\
\hline Distal & $B$ & 2.30 & 2.59 & & & . \\
\hline
\end{tabular}

*Values not statistically significant. 
Treatment change and Post-treatment change in mesial intermolar width of 22 cases.

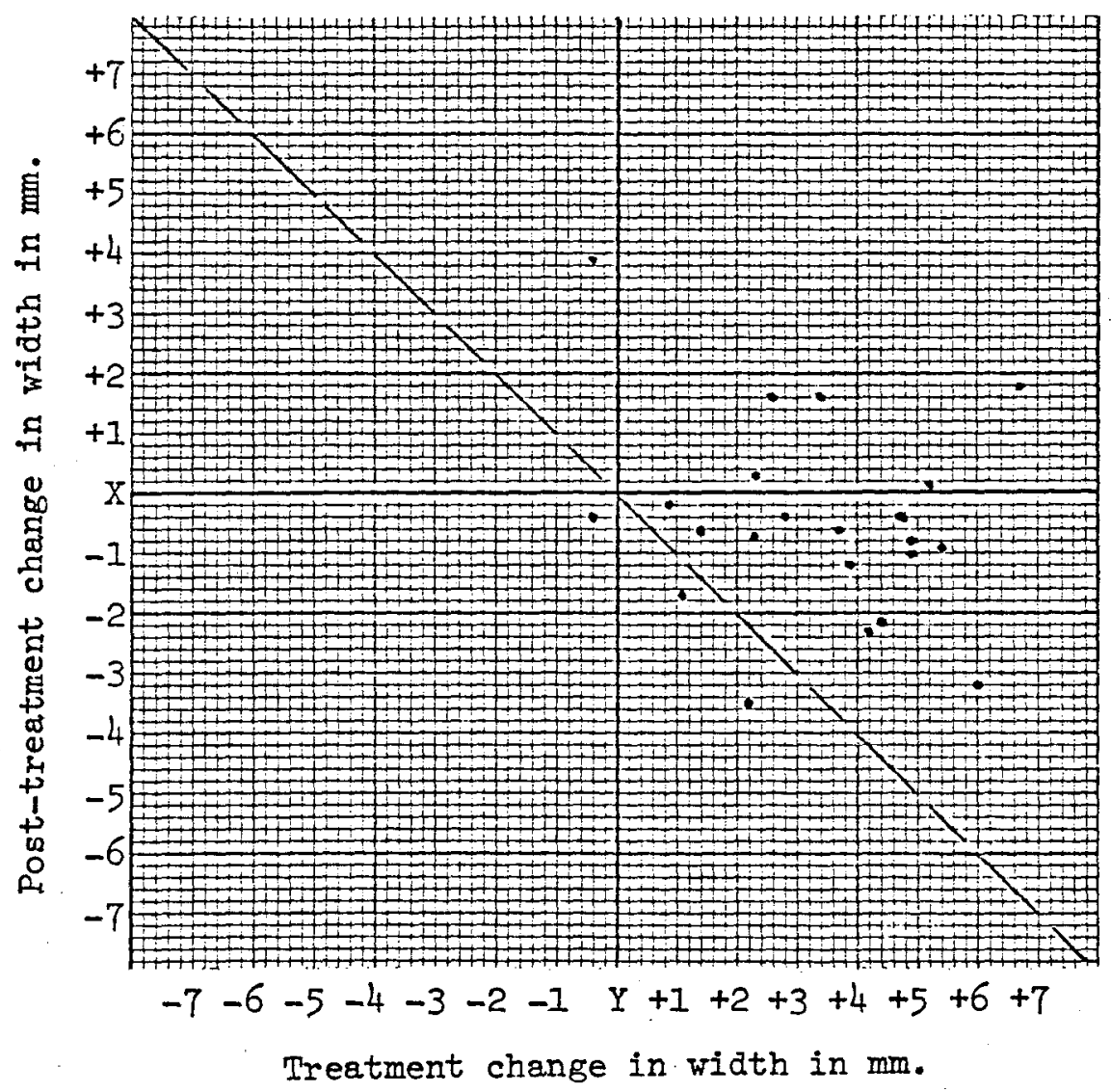

On $Z$ axis - Original and Post-retention mesial intermolar widths the same.

Below $\mathrm{Z}$ axis - Effective decrease in width.

Above $Z$ axis - Effective increase in wiath. 
Treatment change and Post-treatment change in distal intermolar width of 22 cases.

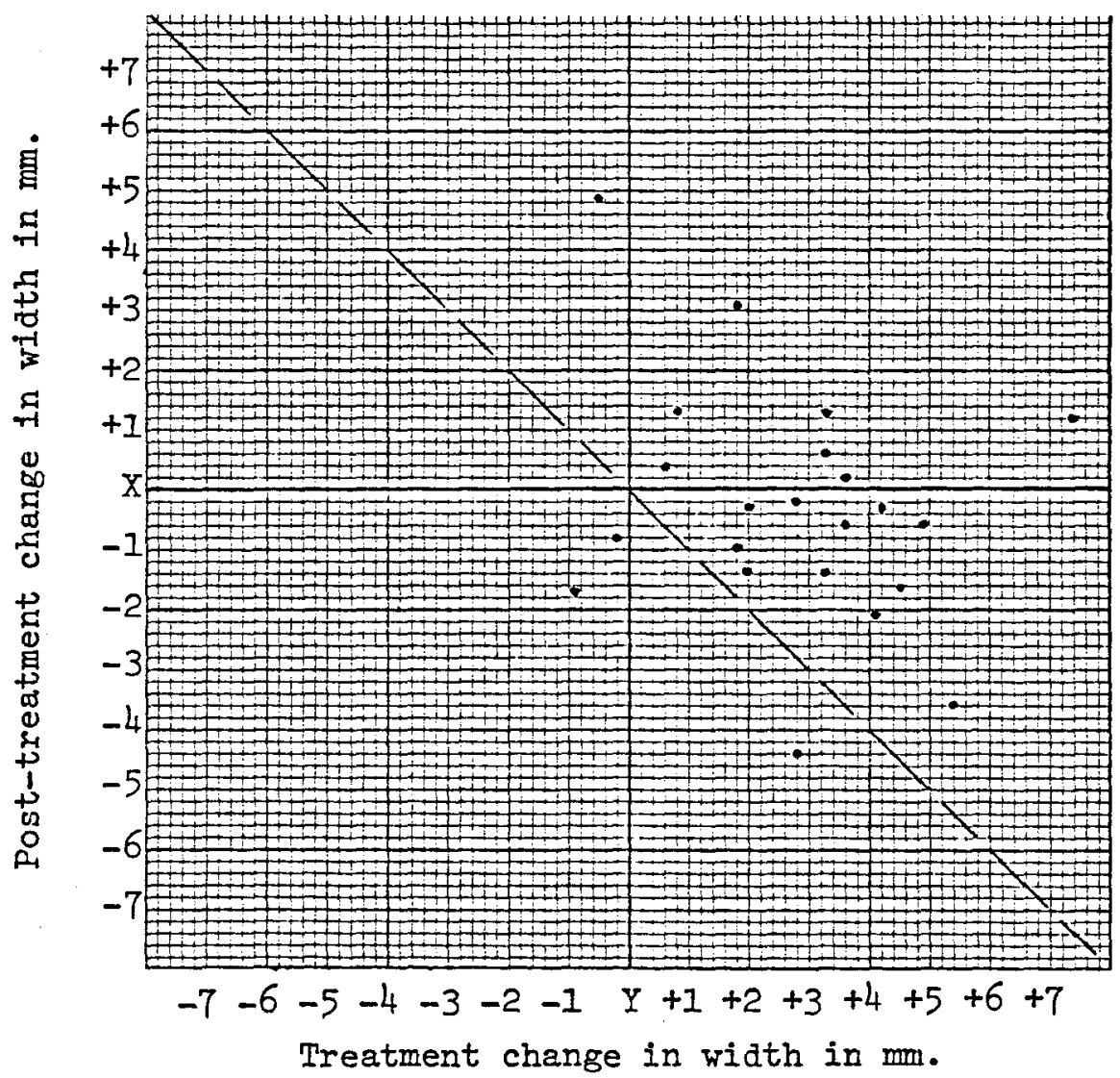

On $\mathrm{Z}$ axis - Original and Post-retention distal intermolar widths the same.

Below $Z$ axis - Effective decrease in width.

Above $Z$ axis - Effective increase in width. 
The graphs display similar patterns between the mesial and distal measurements, with a slight variation in the frequency of each pattern. The observations regarding the frequency of the resultant mesial and distal intermolar widths may be summarized as follows:

1. Sixty-eight percent of the mesial and $55 \%$ of the distal measurements exhibited a pattern of treatment increase with subsequent post-retention decrease.

2. Twenty-three percent of the mesial and $32 \%$ of the distal measurements displayed a pattern of increase with a further post-retention increase.

3. One case of the mesial and two cases of the distal measurements displayed a treatment decrease followed by a post-retention decrease.

4. In both graphs, one case showed a treatment decrease with a post-treatment increase.

5. In both the mesial and distal measurements, nineteen cases or $86 \%$ of the sample demonstrated a net increase of $0.75 \mathrm{~mm}$. or greater.

6. Sixty-eight percent of the mesial and $64 \%$ of distal measurements show a net increase greater than $2 \mathrm{~mm}$. Table IV in the Appendix is a summary of the cephalometric data of the sample. It lists for each patient the normal means and the actual measurements of:

1. Facial Depth

2. Facial Axis 
3. Lower Facial Height

4. Mandibular Arc

5. Mandibular Plane Angle

The Ricketts facial type index and the "Resultant" canine, mesial, and distal molar widths are also listed.

Figure 12 is a histogram representing the frequency of the facial type distribution of the entire sample. The $x$ axis displays the facial type index. It indicates the mean and includes up to \pm 2.5 clinical deviations. The $Y$ axis represents the number of patients that fall into each category. A minus (-) sign indicates a dolicofacial tendency. A $(+)$ sign indicates a brachyfacial tendency. It is obvious from the graph that this sample displays a tendency toward the dolicofacial type, with 19 patients falling on the minus side, 1 on the mean, and 8 on the plus side.

In Figure 13, the resultant widths of the canines are plotted against the facial type index of each individual case. Figure 14 and 15 plot the facial type index against the "Resultant change" in the mesial and distal intermolar widths respectively. In these figures, the $x$ axis or independent variable represents the facial type index, and $Y$ axis or dependent variable represents the resultant change of the canines in milimeters.

Table VII displays the results of the correlations between the "Resultant changes" of the canine, mesial and 
distal molar widths and the facial type indices of their respective sample, i.e. the correlation between the $X$ and $Y$ axis of Figures 12 to 14 . The $t$ values and the $P$ values are also listed in order to verify the level of significance of the correlations. The results show that there is no correlation between the "Resultant" canine, mesial molar, and distal molar widths and the facial type index of the members of their corresponding sample.

Table VIII displays the results of the correlations between the "Resultant changes" of the canine, mesial and distal molar widths and the age of the corresponding sample at initiation of treatment. The $t$ values and $P$ values are also listed in order to verify the level of significance of the correlations. The results show that there is no correlation between the "Resultant" canine, mesial molar, and distal molar widths and the age of the sample at initiation of treatment. 
FIGURE 12

Histogram of the frequency of the facial type distribution of the sample.

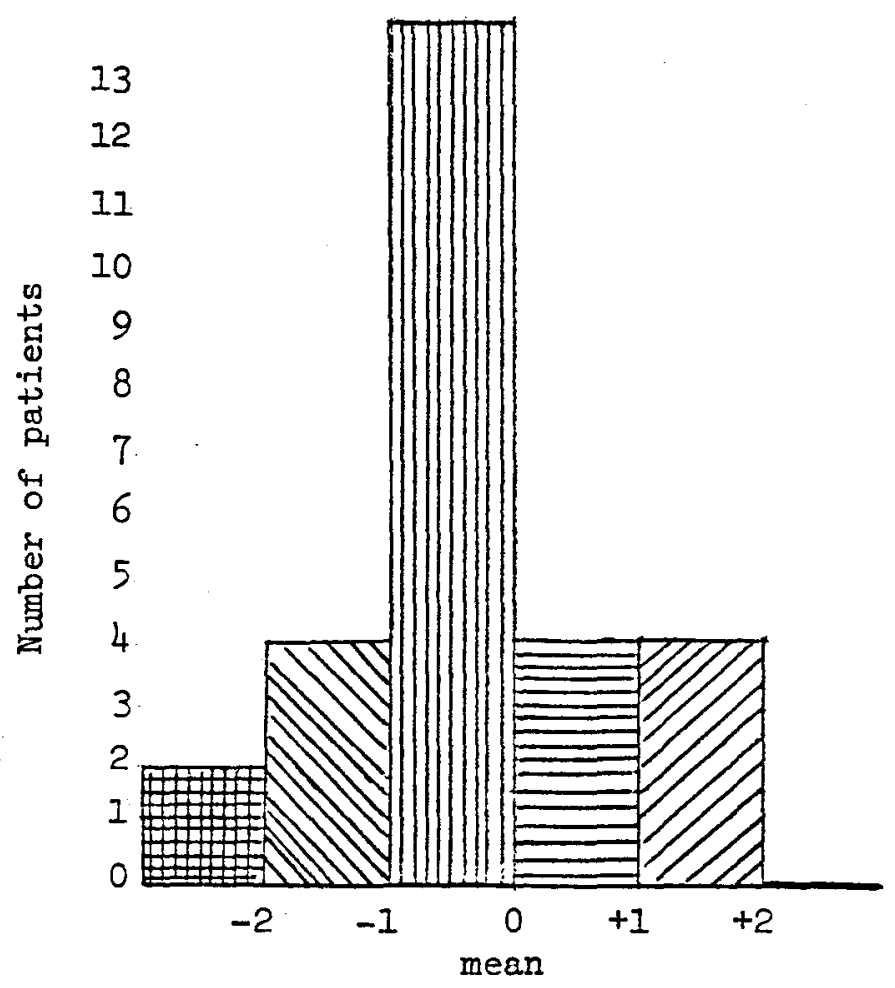

Facial Type Index 
FIGURE 13

Intercanine Resultant change in width, as related to the Facial Type Index of the initial lateral cephalograms.

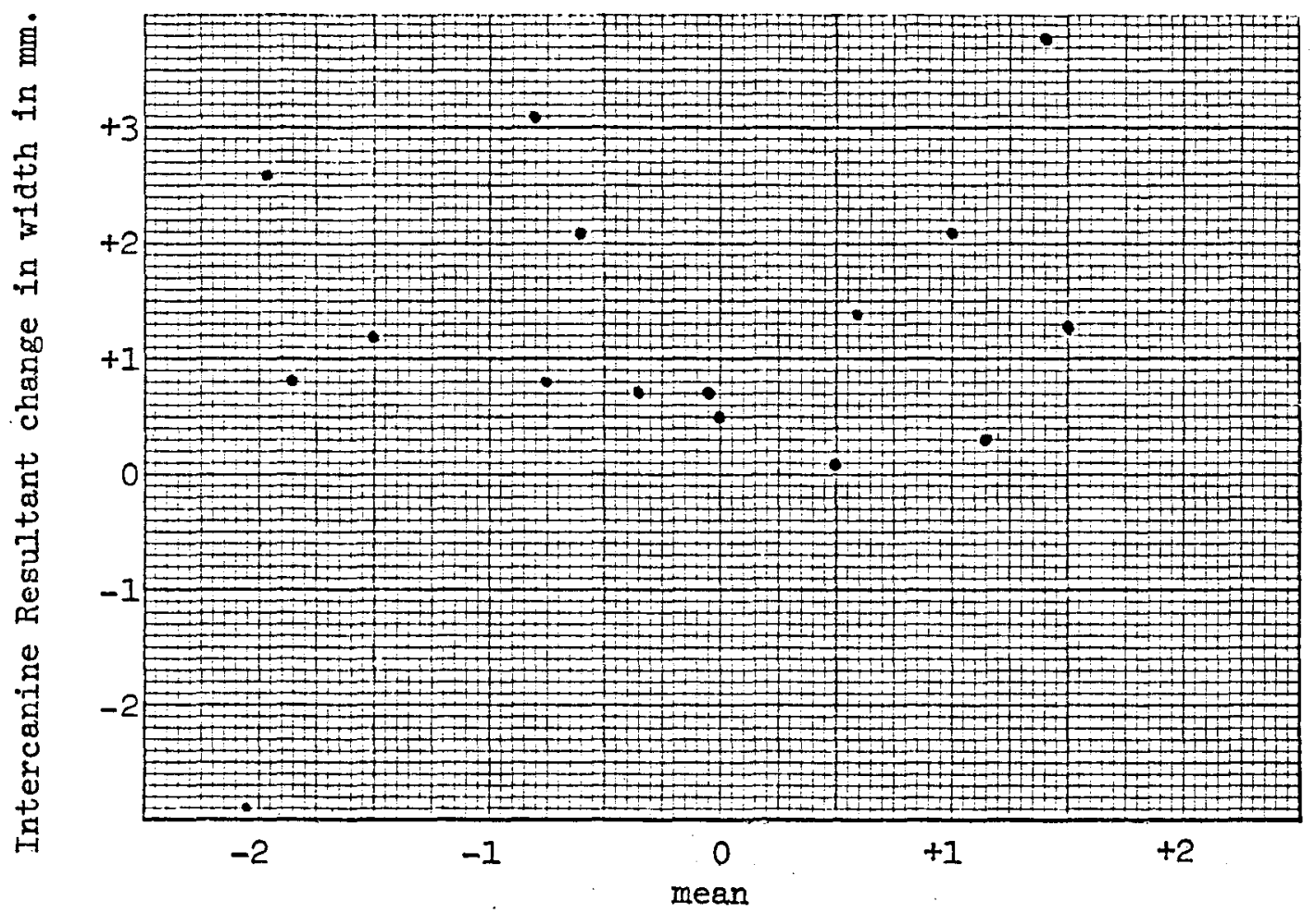

Facial Type Index 
Mesial Intermolar Fesultant change in width as related to the Facial Type Index of the initial lateral cephalograms.

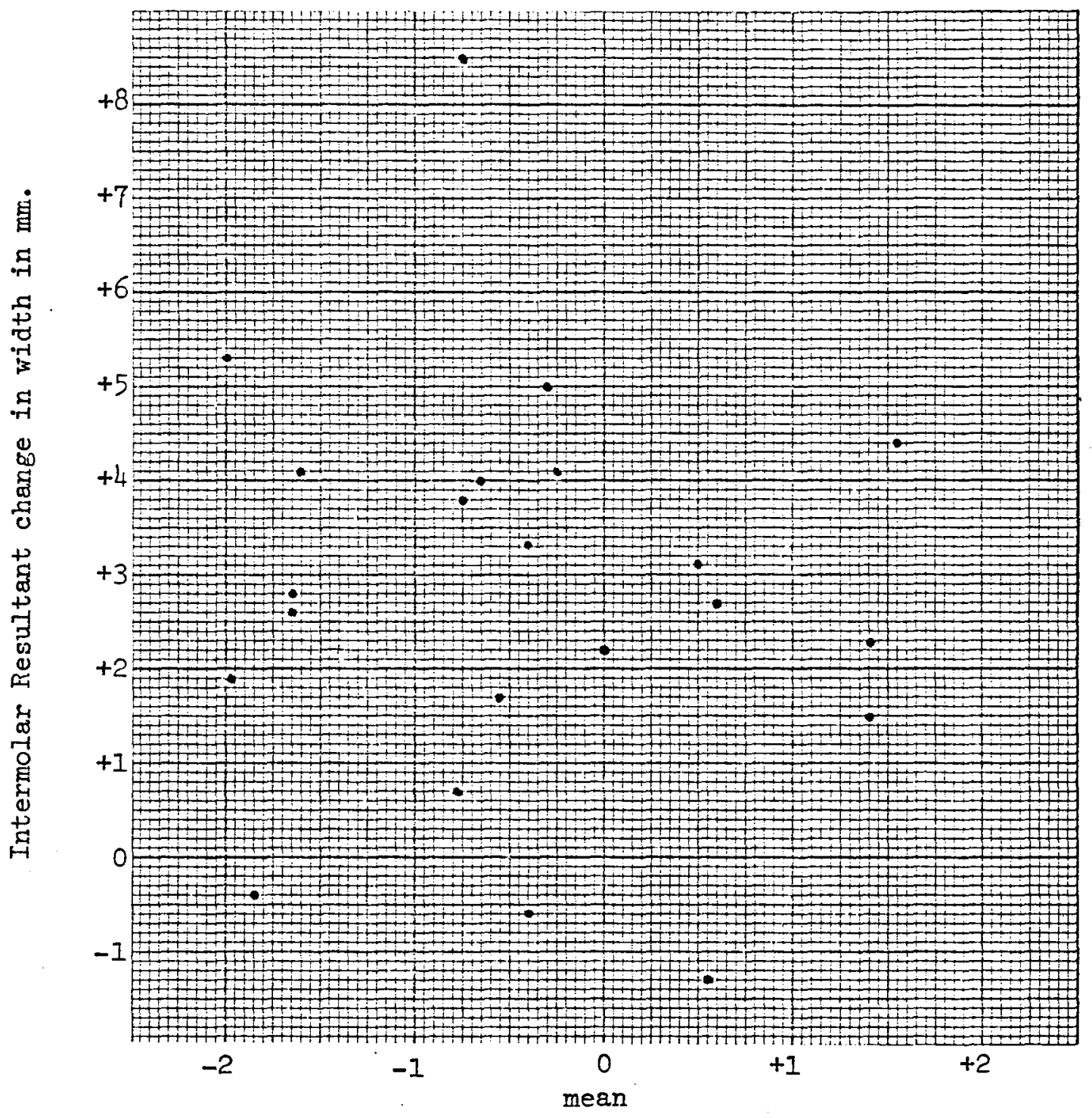

Facial Type Index 
Distal Intermolar Resultant charge in width as related to the Facial Type Index of the initial lateral cephalograms.

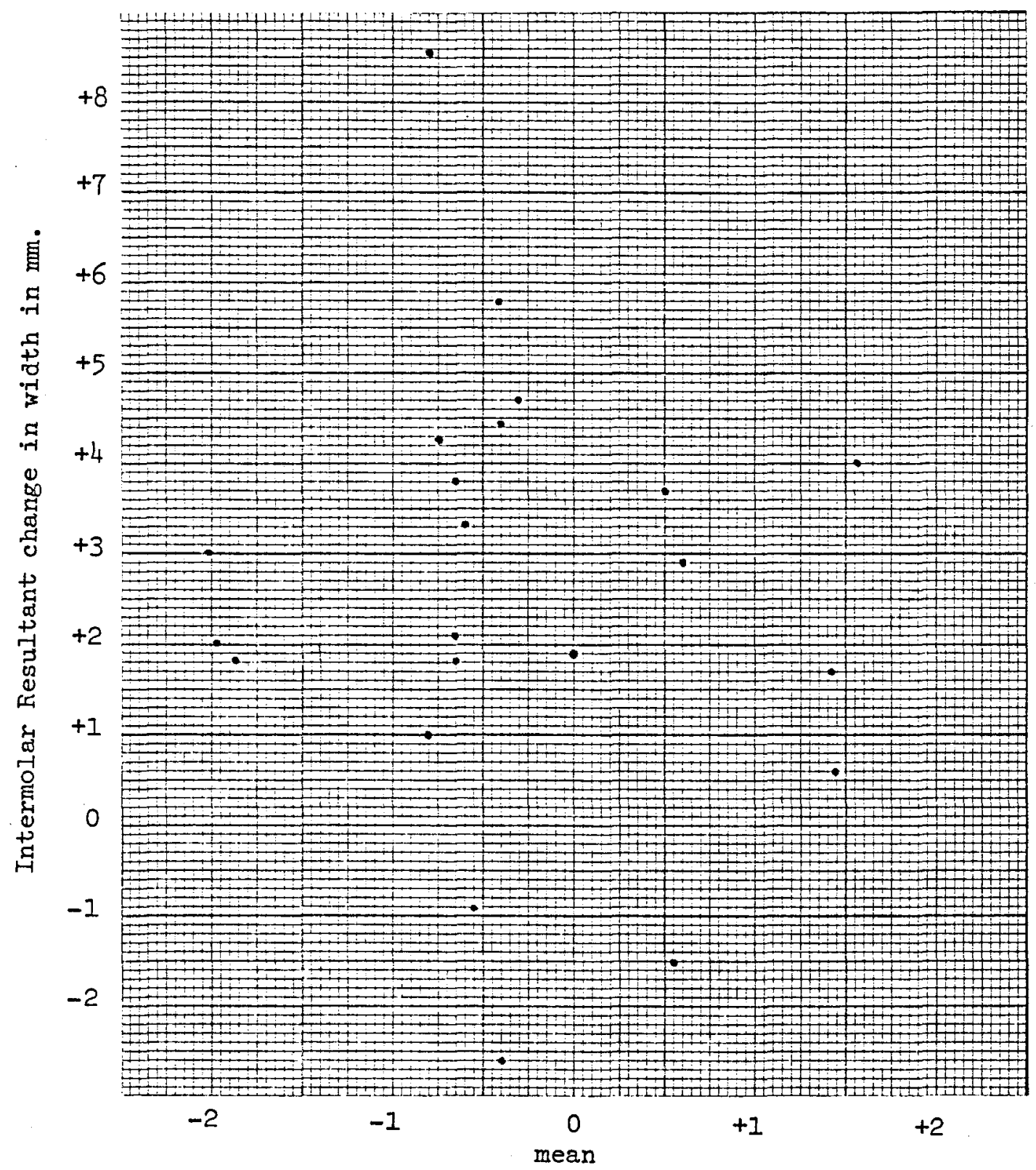

Facial Type Index 


\section{TABLE VII}

Summary of the correlations and $t$ tests between the "Resultant changes" of the intercanine, mesial, and distal intermolar widths, and the Facial Type Indices of their respective sample.

Canine

$$
0.28
$$

1.16

P $0.10 *$

Mesial Molar

$-0.05$

0.25

P $0.10 *$

Distal Molar

$-0.05$

0.25

P $0.10^{*}$

*Values not statistically significant. 
FIGURE 16

Intercanine Resultant change in width as related to the age of the sample at initiation of treatment.

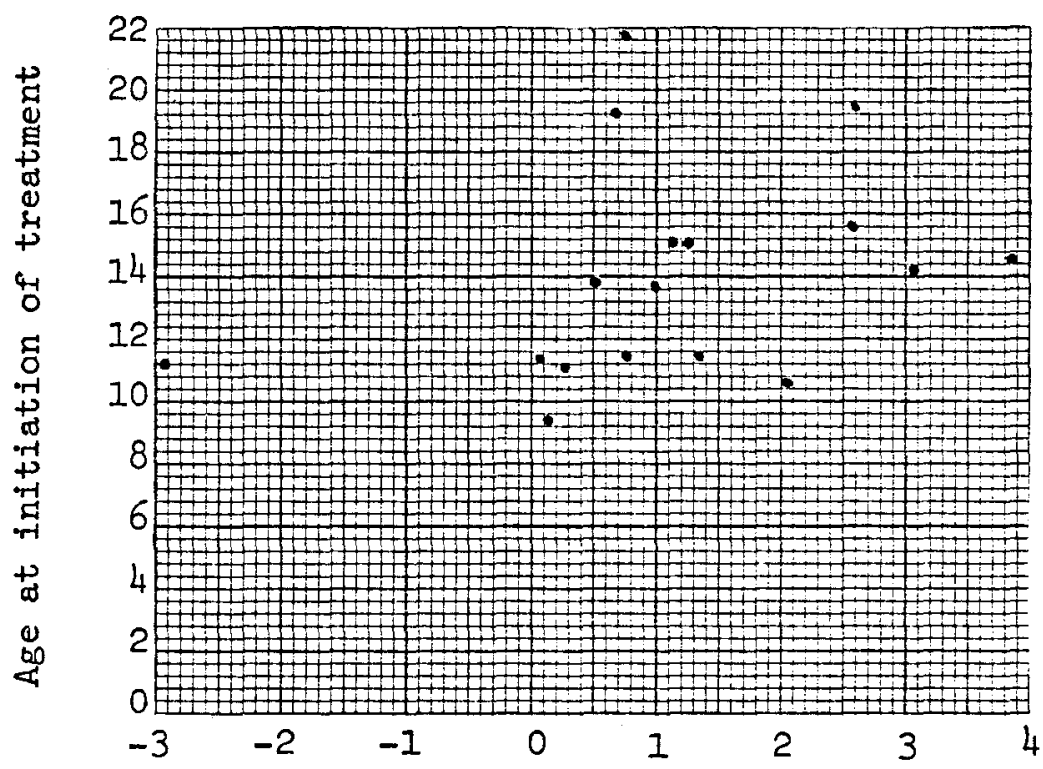

Intercanine Resultant change in width in $\mathrm{mm}$. 
Mesial and Distal Intermoler Resultant change in width as related to age of the sample at initiation of treatment.
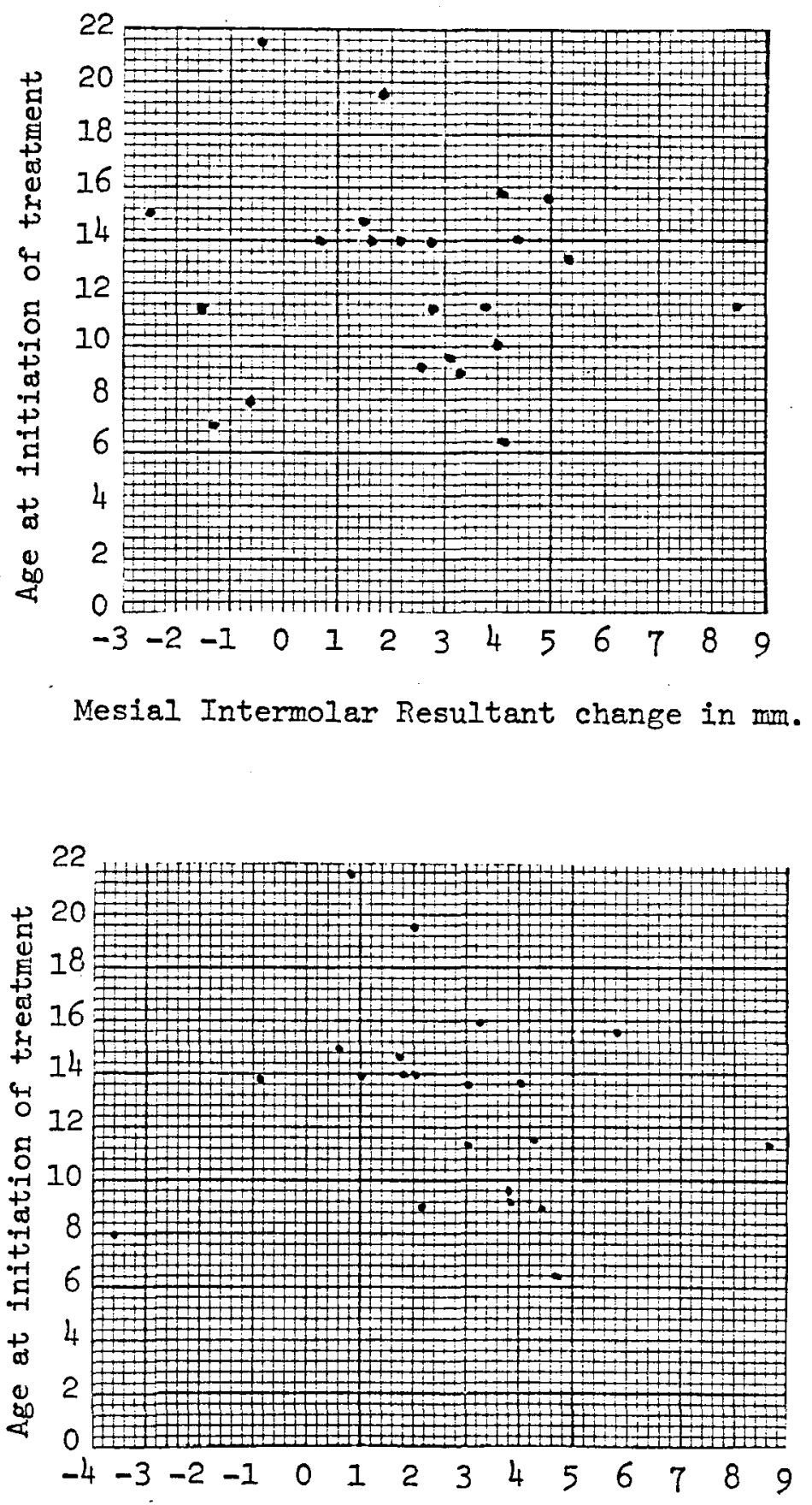

Distal Intermolar Resultant change in $\mathrm{mm}$. 


\section{TABLE VIII}

Summary of the correlations and $t$ tests between the "Resultant changes" of the intercanine, mesial, and distal intermolar widths, and the corresponding age of the sample at initiation of treatment.

\begin{tabular}{lcccc}
\hline Dimension & Correlation & $t$ & $\mathrm{P}$ \\
\hline & 0.30 & 1.16 & $\mathrm{P}$ & $0.10^{*}$ \\
Canine & -0.13 & 0.38 & $\mathrm{P}$ & $0.10^{*}$ \\
Mesial Molar & -0.05 & 0.25 & $\mathrm{P}$ & $0.10^{*}$ \\
Distal Molar & & & & \\
\hline
\end{tabular}

*Values not statistically significant. 
CHAPTER V

\section{DISCUSSION}

The results of this study indicate that a significant expansion of the mandibular intercanine and intermolar widths may be achieved when the orthodontic treatment is combined with rapid maxillary expansion.

The sample was carefully selected for this study and was required to meet strict criteria, in order to insure reliable results. The following three criteria were established for the sample selection:

1. The first criterion required the presence of both permanent molars or canines in the initial study models for the study of their respective widths. This is in contrast to previous studies 5,14 which assumed that the tip of the deciduous canines or the center of the alveolus in the canine region could be used as landmarks representing the actual position of the permanent canines. It has been shown ${ }^{22}$ that even though only a very small increase in width of $0.34 \mathrm{~mm}$. occurs in the transition from the primary to the permanent canines, the standard deviation is \pm 1.7 $\mathrm{mm}$. This range is very large compared to the treatment 
effects seen, for attempting to utilize the deciduous canines as a base from which to study the minute changes in interarch dimensions in the succedaneous canines.

2. The second criterion for selection required the cases in this study to be at least two years devoid of any retention appliances. A minimum of two years was felt to be adequate time for the bulk of the post-treatment relapse to occur.

At the University of Washington, where numerous studies have been performed $3,11,46$, it has been stated that at least a five year post-retention period is necessary to evaluate the stability of the treated dentition. According to welch 46 , this point was "discussed in detail, and convincingly illustrated by Arnold", in his thesis ${ }^{3}$. Arnold drew upon the "clinical experience of the staff of the Department of Orthodontics," and from the "consensus of their opinions," he deduced that "five years out of retention is the minimum time interval for such evaluation." This is definitely a subjective criterion which has not been scientifically proven. He further attempted to illustrate his point with one case which developed crowding of the incisors, and according to him, a $2.5 \mathrm{~mm}$. decrease of the intercanine width, between the end of the first and the fifth year post-retention. This change might have actually occurred between the first and second, or third, or fourth year. After studying carefully the photographs of this case as were presented in his thesis, it 
is the author's impression that minimal, if any decrease of the intercanine width occurred. Furthermore, as proved by Gallerano ${ }^{13}$, crowding of the incisor area does not necessarily indicate a decrease of the intercanine width. In any event, one case does not form scientific data. Until research has proven otherwise, we believe that two years is a valid time interval to allow significant relapse of the interarch dimension to occur.

3. The third criterion required that for the study of the changes in the intermolar width, only non-extraction cases were to be selected. Extraction cases were not accepted since it has been shown that in premolar extraction cases the intermolar width is significantly reduced ${ }^{3,36}$.

For the study of the changes of the intercanine width, a combined sample of extraction and non-extraction cases was used. Although some clinicians 20,43 hypothesized that a greater intercanine expansion may be accomplished through their distal movement into the extraction sites, it has been proven that there is no significant difference between the intercanine expansion found in extraction and non-extraction $\operatorname{cases}^{3}$, and that the amount of distal movement of the canines into the premolar extraction space has no effect on increasing the amount of resultant intercanine width 39,46 .

An important aspect of this study is that the entire sample was treated by one clinician, according to his 
particular technique. Dr. Haas has been practicing edgewise orthodontics for approximately 25 years. He is one of the foremost proponents of the Rapid Maxillary Expansion procedure. His particular treatment objective 17,18,19, appliance design 16,18 , screw manipulation ${ }^{16,18}$, and retention time ${ }^{18}$, are of great significance and bearing on the results of this study.

The method followed to measure the changes in interarch width was also carefully determined. All dimensions were measured independently by two investigators in order to verify the accuracy in transferring the points from one cast to another, and to eliminate bias. All the statistical tests were performed separately on each investigator's data to verify that the measurements of both investigators led to the same conclusions. INTERCANINE WIDTH

There was a mean increase of the intercanine width of $1.1 \mathrm{~mm}$. which held post-retention, indicating that $52 \%$ of the expansion achieved during treatment was retained. The displayed expansion was statistically significant at $P=.005$.

In all cases except one, the intercanine width was increased during treatment. This increase was followed by a subsequent decrease post-retention. The case which did not display this pattern was one of the two cases in which the lower arch was not banded. This case displayed a decrease both during orthodontic treatment and after the end of 
retention. Of the cases which were expanded during treatment, all except one retained some expansion of the intercanine width, post-retention.

The pattern of treatment increase with post-treatment decrease which was observed in the present study is in accordance with investigations $1,3,11,36,46$ regarding the changes of intercanine width after conventional orthodontic treatment. However, in this sample, only $48 \%$ of the expansion gained during treatment was lost post-retention, as compared to a loss of $77 \%$ observed by Welch ${ }^{46}, 76.3 \%$ observed by Amott ${ }^{1}, 71.4 \%$ observed by Bishara et. al. ${ }^{5}$, and $58 \%$ observed by Gardner and Chaconas ${ }^{14}$.

In this study, $94 \%$ of the cases which displayed an increase of the intercanine width during treatment, retained a net expansion post-retention. The number of cases gaining in net intercanine width is greater than the one observed by Arnold ${ }^{3}$, who found only $56 \%$ of his cases displaying a net gain, and by Welch 46 , who reported only $26 \%$ of his sample showing a net gain in intercanine width.

The mean net expansion in the intercanine width of $1.1 \mathrm{~mm}$. found in this study is greater than the net expansion of $0.22 \mathrm{~mm}$. shown by Bishara et. al. ${ }^{5}, 0.52 \mathrm{~mm}$. shown by Welch ${ }^{46},-0.17 \mathrm{~mm}$. shown by Donall, $0.51 \mathrm{~mm}$. in extraction and $0.58 \mathrm{~mm}$. in non-extraction cases shown by Gardner and Chaconas ${ }^{14}$, and $-0.4 \mathrm{~mm}$. shown by Shapiro ${ }^{36}$. 
It is interesting to note that the net expansion found in the previously cited studies is not a statistically significant treatment effect. Significant results were obtained only when the samples in two of the studies, by Amott $^{1}$ and Shapiro ${ }^{36}$, were divided according to malocclusions. Their results indicated that a significant expanison may be obtained in Class II, division 2 cases when analyzed separately. In the present study, not one single case was a Class II, division 2 malocclusion, which makes the $1.1 \mathrm{~mm}$. net expansion in this sample an even more significant finding.

The expansion found in this study is clearly the result of treatment and not growth, since the presense of the permanent canines in the initial models was required. It has been shown $4,6,22,29,40$ that there is no further increase in the intercanine width to be expected after the eruption of the permanent canines, but a decrease is possible ranging from $0.5 \mathrm{~mm}$. to $1.5 \mathrm{~mm}$.

To conclude, patients treated with rapid maxillary expansion exhibited a significant expansion of the intercanine width, appearing to be more stable than those treated with conventional orthodontics. Hence, this study does not support the "inviolability of intercanine width" as had been suggested by McCauley and Strang, and more recently by Donall, Amott ${ }^{1}$, Arnold ${ }^{3}$, Bishara et. al. ${ }^{5}$, welch ${ }^{46}$, Shapiro ${ }^{36}$, and Gardner and Chaconas ${ }^{14}$. 
INTERMOLAR WIDTHS

There was a mean net increase of $2.8 \mathrm{~mm}$. of the mesial and $2.5 \mathrm{~mm}$. of the distal intermolar width. Eighty-five per cent of the mesial and $89 \%$ of the distal increase in width during treatment was retained, indicating that the expansion of this structure is highly stable. The displayed expansion was statistically significant at $P=.0005$.

The predominant occurrence was that of increase of the intermolar width during treatment. After the retention appliances were removed, the mesial points showed a decrease of the width in $68 \%$ of the cases, while an increase in width was noted in $23 \%$ of the cases. The distal points displayed a post-treatment decrease of width in 55\% of the cases, and a post-treatment increase in $32 \%$ of all cases. In addition to this, the mesial points lost an average of $15 \%$ of the original expansion gained during treatment, while the distal points lost $11 \%$. The difference in the pattern of changes in width between the mesial and distal points of the molars can be attributed to some rotational movement occurring during treatment. However, the changes in pattern between the mesial and distal of the molar were not statistically significant, therefore, it may concluded that the movement of the molars was a primarily lateral one rather than rotational.

In order to compare the results of the present study to other investigations, the mesial intermolar net expansion 
was evaluated, since it is this point that the other studies $^{1,3}, 11,14,36,46$ have selected for their measurements. The findings indicate that the net mesial intermolar expansion achieved in this study, with orthodpedic maxillary expansion, was $2.8 \mathrm{~mm}$. $\pm 2.2 \mathrm{~mm}$. S.D. This is greater than the $1.2 \mathrm{~mm}$. $\pm 1.5 \mathrm{~mm}$. S.D. found in Dona's ${ }^{11}$ non-extraction sample, and greater than the 0.9 $\mathrm{mm}$. $\pm 1.3 \mathrm{~mm}$. S.D. found in Arnold's $\mathrm{s}^{3}$ non-extraction sample. It is also greater than the $2 \mathrm{~mm}$. $\pm 1.8 \mathrm{~mm}$. S.D. found by Gardner and Chaconas ${ }^{14}$, and than the $1 \mathrm{~mm} . \pm 1.9$ S.D. found in Shapiro's 36 sample. Even in Class II, division 2 cases, Shapiro found a net intermolar expansion of $1.5 \mathrm{~mm}$., which is still less than that found in this study. This is quite significant when considering that this sample did not include class II, division 2 cases.

Concerning the changes in the intermolar width occurring with growth, it has been shown ${ }^{30}$ that from the time the molars erupt, at an average age of 7 , until 12 years of age, there is a mean increase in width of $1.5 \mathrm{~mm}$. in an untreated population. After this age, studies $9,30,38$ have indicated that the intermolar width remains fairly stable, with no statistically significant changes occurring. In the present investigation, the sample used for the study of intermolar widths had a mean age at the initiation of treatment of 12.6 years, with half of the group being younger than this. Although this sample is too 
small to divide and analyze statistically according to age, it is of interest to note that the mean expansion for the cases under twelve years of age is $3.5 \mathrm{~mm}$., which is greater than the $2.8 \mathrm{~mm}$. found for the entire sample. Furthermore, of the eight cases which displayed a pattern of treatment increase with a further post-treatment increase, six of them were under 12 years of age. It may be concluded, that any increase in width occurring before the age of 12 , which may have occurred as a result of growth, definitely does not preclude the fact that there was a singificant additional expansion obtained as a result of treatment.

Overall, this study shows that a significant expansion of the molars is possible when orthodontic treatment is combined with the use of rapid maxillary expansion and that a significant percentage of this expansion remains after retention is removed. RELATION OF FACIAL TYPING AND AGE, TO MANDIBULAR EXPANSION In an effort to explain why some cases retained a greater percentage of expansion than others, we attempted to correlate the facial typing determined from the initial lateral cephalogram, and age at initiation of treatment, to the amount of expansion retained post-retention. The findings indicated that both the facial pattern, and the age - at initiation of treatment, were not related to the amount of intra-arch expansion retained post-retention, although the frequency distribution of this sample was skewed toward 
the dolichofacial pattern. This held true both for canines and molars.

There is a widespread notion in orthodontics that brachyfacials can afford a greater expansion, and remain more stable than other facial types. This notion is probably based on the fact that Class II, division 2 cases have been proven ${ }^{1,36}$ to retain a greater orthodontic expansion of the lower arch than other malocclusions. Before formulating conclusions regarding this statement, it should be considered that class II, division 2 is an indicator both of a brachyfacial type, and a specific dental relationship. The possibility exists, to be examined in future studies, that the greater potential for retention of expansion is not due to facial type, but rather because the lower teeth are usually enclosed in the upper dentition, being therefore, lingually positioned by the excessive overbite of the maxillary anteriors.

The only studies which could be interpreted as attempting to relate the facial types with the expansion of the lower arch, are those described by Schulhof et. al. 37 in 1968. It was shown in these studies that the intermolar width was statistically correlated to the Lower Facial Height of the initial lateral $x$-ray and, the molar to jaw relationship of the final frontal $x$-ray. This does not sustain that brachyfacials have a greater potential of retaining expansion, since Lower Facial Height is only one 
of several indicators of facial type, and the difference between the two groups studied was less than 1 standard deviation. The intercanine width was then related to facial type and tooth mass, and a formula was described which indicated that a patient with a brachyfacial pattern will have a wider mandibular arch than the dolichofacial. It was later proven 37 that cases which were expanded $1 \mathrm{~mm}$. or more beyond their individualized norm, displayed a greater relapse than those treated to the norm. In other words, nature may have bestowed wider arches to the brachyfacial population. However, this study does not prove that brachyfacials can tolerate more expansion than dolichofacials.

The present study confirms that a significant expansion of the mandibular intercanine and intermolar width can be obtained when orthodontic treatment involves rapid palatal expansion, and that there is no relationship between the retained expansion and facial typing. It does not however provide and explanation of why cases treated with palatal expansion tend to retain a significant increase of the lower arch, or why the sample presents a large variation among individuals in the amount of expansion retained.

Concerning the first question, it has been speculated 16,19 that the stability of the intercanine and intermolar width may be due to the lateral movement of the maxillae, which carry the buccinator attachments laterally, 
therefore changing the previous muscle balance exerted on the dentition by the tongue and buccal musculature. The altered forces of occlusion produced by the maxillary dental expansion may also influence the expansion of the lower arch. Factors which might contribute to the variation in the expansion retained, may be related to the amount of initial incisor crowding, or the initial intra-arch width. Another factor may be the difference between the initial arch width of each individual and their respective arch width according to the individualized norms, correlated to the amount of expansion retained. The lingual inclination of the mandibular buccal segments, in the initial models as correlated to the amount of expansion attained may also be another possibility. All these factors should be analyzed individually and collectively in order to determine a possible relationship of them to the stability of the lower arch.

The changes in skeletal pattern in the final lateral cephalogram (growth direction), or separate individual cephalometric variables either in the initial or final $x$-ray may also be related to the amount of expansion retained.

All these hypotheses can form the basis for future studies, in order to further delineate the relevant factors for precisely predicting how much the lower canines and molars can be confidently expanded in a given patient. 


\section{SUMMARY AND CONCLUSION}

This study was performed to determine the stability of the intercanine and intermolar widths of the lower arch when orthodontic treatment was combined with rapid maxillary orthopedic expansion. The relationship between facial typing at the initiation of treatment, and the net expansion retained post-retention, was also studied.

Initial, final, and at least two years postretention models were analyzed. The sample consisted of 17 cases for the study of the intercanine width, and 22 non-extraction cases for the study of the intermolar width. The measurements were recorded with a digitizer connected to a 360 IBM computer. They were performed twice by two separate investigators to determine the reliability of the method.

Treatment and post-retention changes, for the intercanine mesial and distal intermolar widths were calculated. These changes were tested for significance with paired t tests.

The initial lateral cephalograms of all patients 
were traced, and their Facial Type Index was calculated (after Ricketts). A correlation was done between the facial typing and the net expansion of the intercanine and intermolar widths retained post-retention.

The following conclusions were drawn from this investigation, regarding patients whose orthodontic treatment was combined with rapid maxillary expansion:

1. The mean expansion of the intercanine width, retained after at least a two year post-retention period, was $1.1 \mathrm{~mm}$. This is statistically significant as compared to its initial width, and higher than the expansion which has been found in conventional orthodontic treatment.

2. The mean expansion of the intermolar width, retained after at least a two year post-retention period, was $2.8 \mathrm{~mm}$. This is statistically significant as compared to its initial width, and higher than the expansion which has been found in conventional orthodontic treatment.

3. No significant association could be demonstrated between the facial typing of the patients in this sample at the initiation of treatment, and the net expansion of the intercanine and intermolar widths retained. 


\section{REFERENCES}

1. Amott, Robert D.: A Serial Study of Dental Arch Measurements on Orthodontic Subjects; Masters Thesis, Northwestern University, 1962.

2. Angle, E.H.: Treatment of Malocclusion of the Teeth; Philadelphia, S.S. White Dental Mfg. Co., Seventh Edition, 1907.

3. Arnold, Manfred L.: A Study of the Changes of the Mandibular Intercanine and Intermolar Widths During Orthodontic Treatment and Following Post-Retention Period of Five or More Years; Masters Thesis, University of Washington, 1963.

4. Barrow, G.V. and White, Jr. R.: Developmental Changes of the Maxillary and Mandibular Dental Arches; Angle Orthod., 22:41-46, 1952 .

5. Bishara, Chadha, Potter: Stability of the Intercanine Width, Overbite and Overjet Correction; Am. J. Orthod., $63: 588-595,1973$.

6. Brown, V.P. and Jensen, D.: Changes in the Dentition from the Early Teens to the Early Twenties; Act. Odont. Scand., 9:177-192, 1951 .

7. Case, Calvin S.: Principles of Retention in Orthodontia; Int. J. of Orthod. and Oral Surg., $6: 627-642,1920$.

8. Christie, T.: Cephalometric Patterns of Adults with Normal Occlusions; Angle Orthod., 47:2;128-135, 1977.

9. Dekock, W.H.: Dental Arch Depth and Width studied Longitudinally from Twelve Years of Age to Adulthood; Am. J. Orthod., 62:56-66, 1972.

10. Derichweiler, H.: "Die Gaumenrahtsperngung"; Fortschritte der Kiefer-orthopadie Band 14: Heft, 1953. 
11. Dona, Aldo: An Analysis of Dental Casts of Patients Made Before and After Orthodontic Treatment; Masters Thesis, University of Washington, 1952.

12. Fauchard, Pierre: The Surgeon Dentist or Treatise on the Teeth, 1728. Translated by Lilian Lindsay, Butterworth and Co. Ltd., 1946.

13. Gallerano, R.L.: Mandibular Anterior Crowding: A PostRetention Study; Masters Thesis, University of Washington, 1976.

14. Gardner, D.S. and Chaconas, S.J.: Post-Treatment and Post-Retention Changes Following Orthodontic Therapy; Angle Orthod., 46:151-161, 1976.

15. Gryson, J: Changes in Mandibular Interdental Distance Concurrent with Rapid Maxillary Expansion; Angle Orthod., $47: 186-192,1977$.

16. Haas, Andrew: Rapid Expansion of the Maxillary Dental Arch and Nasal Cavity by Opening the Mid-Palatal Suture, Angle Orthod., 31:73-90, 1961 .

17. Haas, Andrew: The Treatment of Maxillary Deficiency by Opening the Mid-Palatal Suture; Angle Orthod., 65:200$217,1965$.

18. Haas, Andrew: Expansion: Just the Beginning of Dentofacial Orthopedics; Am. J. Orthod., 57:219-254, 1970 .

19. Haas, Andrew: Long-term Post-treatment Evaluation of Rapid Palatal Expansion; Angle Orthod., 50:189-217, 1980.

20. Howes, Ashley: Arch width in the Premolar Region, Still the Major Problem in Orthodontics; Am. J. Orthod., $43: 5-31,1957$.

21. Howes, Ashley: Expansion as Treatment Procedure, where Does it Stand Today?; Am. J. Orthod., 46:515-534, 1960.

22. Knott, Virginia: Longitudinal Study of Dental Arch Widths at Four Stages of Dentition; Angle Orthod., 42:200-213, 1972 .

23. Korkhous, G.: Discussion of Report: A Review of Orthodontic Research (146-1950); Internat. D.J., 3:356, 1953. 
24. Korkhaus, G.: Present Orthodontic Thought in Germany; Am. J. of Orthod., 46:187-206, 1960.

25. Krebs, A.: Expansion of the Mid-palatal Suture Studied by Means of Metallic Implants; European Ortho. Society Trans., $34: 163,1958$.

26. Litowitz, Robert: A Study of the Movements of Certain Teeth During and Following Orthodontic Treatment; Angle Orthod., 18:113-131, 1948 .

27. Lundstrom, A.S.F.: Malocclusion of the Teeth Regarded as a Problem in Connection with the Apical Base; Int. J. Orthod. and Oral Surg., 11:591-602, 1925.

28. McCauley, D.R.: The Cuspid and its Function in Retention; Am. J. Orthod., 30:196-205, 1944.

29. Moorrees, C.F.A. and Chadha, M.J.: Available Space to the Incisors During Dental Development, A Growing Study Based on Physiologic Age, Angle Orthod., 35:12-22, 1965.

30. Moyers, R.E., F.P.G.M. van der Linden, M.L. Riolo and J.A. MCNamara: Standards of Human Occlusal Development, Monograph Number 5, Craniofacial Growth Series, The Center for Human Growth and Development, The University of Michigan, Ann Arbor, 1976.

31. Nance, H.N.: The Limitations of Orthodontic Treatment; Am. J. Orthod. and Oral Surg., 33:253-301, 1947.

32. Pterovic, A.G., J.J. Stutzmann, C.L. Oudet: Control Processes in the Postnatal Growth of the Condylar Cartilage of the Mandible; Determinants of Mandibular Form and Growth, Monograph No. 4, Craniofacial Growth Series, Center for Human Growth and Development, The University of Michigan, Ann Arbor, 1975.

33. Ricketts, R.M., R.W. Beuch, C.F. Gugino, J.J. Hilgers, R.J. Schulhof: Bioprogressive Therapy, Rocky Mountain Orthodontics, 1971 .

34. Ricketts, R.M. et. al.: An Overview of Computerized Cephalometrics; Am. J. Orthod., 61:1, 1-28, 1972.

35. Riedel, Richard: Post Pubertal Occlusal Changes in: The Biology of Occlusal Development, Monograph Number 7, Craniofacial Growth Series, The University of Michigan, Ann Arbor, Michigan. 
36. Shapiro, P.A.: Mandibular Arch Form and Dimension; Am. J. Orthod., 68:58-70, 1974 .

37. Schulhof, R.J.: The Mandibular Dental Arch - Part III Buccal Expansion; Angle Orthod., 48:303-310, 1978.

38. Sillman: Dimensional Changes of the Dental Arches: Longitudinal Study from Birth to 25 years; Am. J. Orthod., 50:824-841, 1967.

39. Sondhi, Anoop: Dimensional Changes in the Dental Arches of Orthodontically Treated Cases; Am. J. Orthod., $77: 1-12,1980$.

40. Speck, N.T.: A Longitudinal Study of the Developmental Changes in Human Lower Dental Arches; Angle Orthod., $20: 215-228,1950$.

41. Steadman: Changes of the Intermolar and Intercuspid Distances Following Orthodontic Treatment; Angle Orthod., 31:207-215, 1961.

42. Strang, R.H.W.: Factors of Influence in Producing a Stable Result in Treatment of Malocclusion; Am. J. Orthod. and Oral Surg., 32:313-332, 1946.

43. Strang, R.H.W.: Factors Associated with Successful Orthodontic Treatment; Am. J. Orthod., 38:790-800, 1952.

44. Tweed, Charles H.: Indications for the Extraction of Teeth in Orthodontic Procedure; Am. J. Orthod. and Oral Surgery, 30:405-428, 1944 .

45. Walter: Comparative Changes in Mandibular Canine and First Molar Widths; Angle Orthod., 32:232-240, 1962.

46. Welch, K.N.: A Study of Treatment and Post-Retention Dimensional Changes in Mandibular Dental Arches; Masters Thesis, University of Washington, 1965.

47. Wertz, R.: Mid-palatal Suture Opening: A Normative Study; Am. J. Orthod., 71:367-381, 1977. 
APPENDIX I A 
TABLE I A

Tabulation of Data

Intercanine Dimensions - Observer A

Intercanine Change in $\mathrm{mm}$.

Case

Number

809

500

1967

1732

1321

120

1414

1462

767

899

1807

1501

906

1279

834

1234

2691
Post-Treatment Change Change

2.43

3.65

1.99

1.74

1.10

$-.08$

2.0

2.20

2.00

0.65

5.27

3.01

2.79

2.12

0.21

2.07

2.83
$-1.13$

$-1.02$

$-1.16$

$-1.29$

$-1.08$

0.45

$-.68$

$-1.73$

$-0.97$

$-3.54$

$-1.08$

$-1.28$

$-0.70$

$-0.66$

$-0.03$

$-0.51$

$-0.19$
Resultant

Change

1.29

2.62

0.83

0.44

0.02

0.37

1. 32

0.47

1.03

$-2.89$

4.19

1. 73

2.10

1.46

0.19

1.56

2.65 
APPENDIX I B 
TABLE I B

Tabulation of Data

Intercanine Dimensions - Observer B

\section{Intercanine Change in $\mathrm{mm}$.}

Case

Number

809
500
1967
1732
1321
120
1414
1462
767
899
1807
1501
906
1279
834
1234
2691

Treatment Change

1.33

5.21

0.92

2.45

0.97

0.83

3.51

2.57

2.86

0.65

2.95

2.26

3.94

3.85

$-0.19$

1.52

2.83
Post-Treatment Change

$-0.68$

$-2.55$

$-0.72$

$-1.36$

$-0.77$

$-0.33$

$-2.11$

$-1.58$

$-1.52$

$-3.55$

0.53

$-1.35$

0.10

$-1.02$

0.09

$-1.48$

$-0.19$
Resultant

Change

0.64

2.66

0.20

1.09

0.21

0.51

1.41

1.00

1.34

$-2.9$

3.48

0.90

4.04

2.83

$-0.10$

0.04

2.65 
APPENDIX II A 
TABLE II A

Tabulation of Data

Mesial Intermolar Dimensions - Observer A

Mesial Intermolar Change in $\mathrm{mm}$.

Case

Number
Treatment

Change

$\begin{array}{rr}1.60 & -0.86 \\ 4.06 & -1.65 \\ 2.24 & 0.43 \\ 5.66 & -3.53 \\ 4.97 & -2.87 \\ -0.90 & 4.25 \\ 5.43 & -0.07 \\ 5.69 & 1.92 \\ 3.18 & 1.31 \\ 3.85 & -0.92 \\ 5.28 & 0.36 \\ 3.76 & -0.59 \\ 4.69 & -0.28 \\ 0.67 & -1.35 \\ 2.55 & 0.07 \\ 3.04 & -0.68 \\ 0.53 & -0.20 \\ 4.63 & -1.00 \\ 1.68 & -3.40 \\ -.49 & -0.03 \\ 4.74 & -0.58 \\ 2.70 & 2.00\end{array}$

Resultant

Change

0.74

2.42

2.67

2.12

2.10

3.34

4.73

7.60

4.49

2.93

5.64

3.16

4.41

$-0.68$

2.62

2.36

0.32

3.63

$-1.72$

$-0.52$

4.16

4.70 
APPENDIX II B 
TABLE II B

Tabulation of Data

Mesial Intermolar Dimensions - Observer B

Mesial Intermolar Change in $\mathrm{mm}$.

Case

Number

809

500

699

299

1967

1438

2479

1732

1489

1321

1858

1717

2141

1978

1807

1501

906

641

2229

1234

2691

2323
Treatment

Change

1. 14

4.30

2.36

6.36

3.77

$-0.36$

5.30

7.71

2.00

3.61

5.16

4.02

5.20

1. 50

2.01

2. 49

1. 35

5.09

2.74

0.05

4.74

4.10
Post-Treatment

Change

$-0.42$

$-2.95$

$-0.08$

$-2.92$

$-1.54$

3.61

$-1.20$

1.68

1.61

$-0.35$

$-0.29$

$-1.72$

$-1.40$

$-2.02$

$-1.54$

$-0.18$

$-0.24$

$-1.08$

$-3.70$

$-0.32$

$-0.58$

1.10
Resultant

Change

0.72

1.35

2.44

3.45

2. 23

3.25

4.10

9.39

3.60

3.26

4.87

2.31

3.81

$-0.51$

0.47

2.31

1.11

4.01

$-0.96$

$-0.27$

4. 16

5.30 
APPENDIX III A 
TABLE III A

Tabulation of Data

Distal Intermolar Dimensions - Observer A

Distal Intermolar Change in $\mathrm{mm}$.

$\begin{array}{lrrr}\begin{array}{l}\text { Case } \\ \text { Number }\end{array} & \begin{array}{l}\text { Treatment } \\ \text { Change }\end{array} & \begin{array}{l}\text { Post-Treatment } \\ \text { Change }\end{array} & \begin{array}{l}\text { Resultant } \\ \text { Change }\end{array} \\ 809 & -0.25 & -0.30 & -0.55 \\ 500 & .4 .30 & -2.07 & 2.22 \\ 699 & 0.91 & 1.44 & 2.35 \\ 299 & 5.26 & -3.96 & 1.30 \\ 1967 & 2.43 & -1.04 & 1.39 \\ 1438 & -1.12 & 4.58 & 3.46 \\ 2479 & 4.50 & 0.02 & 4.52 \\ 1732 & 7.17 & 1.69 & 8.86 \\ 1489 & 3.11 & 1.04 & 4.15 \\ 1321 & 3.64 & -0.11 & 3.53 \\ 1858 & 3.04 & -0.60 & 2.44 \\ 1414 & 4.41 & -1.35 & 3.06 \\ 2141 & 3.28 & 1.24 & 4.52 \\ 1978 & -1.26 & -1.06 & -2.32 \\ 1807 & 1.24 & 0.31 & 1.55 \\ 1501 & 1.50 & -1.20 & 0.30 \\ 906 & 0.62 & 0.22 & 0.40 \\ 641 & 4.82 & -0.55 & 4.27 \\ 2229 & 3.21 & -4.60 & -1.40 \\ 1234 & 2.08 & -0.31 & 1.77 \\ 2691 & 4.03 & -0.73 & 3.30 \\ 2323 & 3.00 & 2.60 & 5.60\end{array}$


Appendix III B 
TABLE III B

Tabulation of Data

Distal Intermolar Dimensions - Observer B

Distal Intermolar Change in $\mathrm{mm}$.

Case

Number

809

500

699

299

1967

1438

2479

1732

1489

1321

1858

1414

2141

1978

1807

1501

906

641

2229

1234

2691

2323
Treatment

Change

0.05

3.81

0.72

5.57

4.26

0.10

3.93

7.70

3.01

3.51

4.15

4.67

3.41

$-0.62$

2.77

2.42

0.52

4.94

2.49

1.47

4.03

2.50
Post-Treatment

Change

$-1.21$

$-2.05$

1.12

$-3.25$

$-1.83$

5.28

$-0.52$

0.71

0.41

0.33

$-0.50$

$-1.95$

1.36

$-2.25$

$-0.85$

$-1.57$

0.99

$-0.55$

$-4.04$

$-1.59$

$-0.73$

3.50
Resultant

Change

$-1.16$

1.75

1.84

2.32

2.43

5.38

3.41

8.42

3.42

3.84

3.65

2.72

4.78

$-2.87$

1.93

0.85

1. 51

4.39

$-1.55$

$-0.11$

3.30

6.1 
APPENDIX IV 
TABLE IV

Facial types according to cephalometric data.

\begin{tabular}{|c|c|c|c|c|c|c|c|}
\hline CASE & FACTOR & $\begin{array}{l}\text { NORMAL } \\
\text { MEANS }\end{array}$ & MEASUREMENT & $\begin{array}{l}\text { FACIAL } \\
\text { TYPE } \\
\text { INDEX }\end{array}$ & $\begin{array}{l}\text { RESULTANT } \\
\text { INTERCANINE } \\
\text { CHANGES }\end{array}$ & $\begin{array}{l}\text { RESULTANT MESIAL } \\
\text { INTERMOLAR } \\
\text { CHANGES }\end{array}$ & $\begin{array}{l}\text { RESULTANT DISTAL } \\
\text { INTERMOLAR } \\
\text { CHANGES }\end{array}$ \\
\hline 809 & $\begin{array}{l}\text { Facial Depth } \\
\text { Facial Axis } \\
\text { L.F.H. } \\
\text { Mand. Arc } \\
\text { F.M.A }\end{array}$ & $\begin{array}{l}88.6 \pm 3 \\
90 \pm 3 \\
47 \pm 4 \\
28.5 \pm 4 \\
24.3 \pm 4\end{array}$ & $\begin{array}{l}92 \\
86 \\
47 \\
20 \\
26\end{array}$ & -0.55 & $1 \mathrm{~mm}$. & $0.7 \mathrm{~mm}$. & $-0.9 \mathrm{~mm}$. \\
\hline 500 & $\begin{array}{l}\text { Facial Depth } \\
\text { Facial Axis } \\
\text { L.F.H. } \\
\text { Mand. Arc } \\
\text { F.M.A }\end{array}$ & $\begin{array}{l}89.3 \pm 3 \\
90 \pm 3 \\
47 \pm 4 \\
29.5 \pm 4 \\
23.6 \pm 4\end{array}$ & $\begin{array}{l}88 \\
82 \\
57 \\
22 \\
34\end{array}$ & -1.99 & $2.6 \mathrm{~mm}$. & $1.9 \mathrm{~mm}$. & $2 \mathrm{~mm}$. \\
\hline 1967 & $\begin{array}{l}\text { Facial Depth } \\
\text { Facial Axis } \\
\text { L.F.H. } \\
\text { Mand. Arc } \\
\text { F.M.A }\end{array}$ & $\begin{array}{l}88.6 \pm 3 \\
90 \pm 3 \\
47 \pm 4 \\
28.5 \pm 4 \\
24.3 \pm 4\end{array}$ & $\begin{array}{l}90 \\
86 \\
47 \\
32 \\
23.5\end{array}$ & 0.0 & $0.5 \mathrm{~mm}$. & $2.2 \mathrm{~mm}$. & $1.9 \mathrm{~mm}$. \\
\hline
\end{tabular}


TABLE IV (continued)

1732 Facial Depth $87.6+3 \quad 86$

Facial Axis $90 \pm 3 \quad 83$

L.F.H. $\quad 47 \pm 4 \quad 47$

Mand. Arc $27 \mp 4 \quad 28$

F.M.A $23.3 \pm 4 \quad 29$

$-0.77 \quad 0.8 \mathrm{~mm} . \quad 8.5 \mathrm{~mm} . \quad 8.6 \mathrm{~mm}$.

1321 Facial Depth $87+3 \quad 87$

Facial Axis $90 \pm 3 \quad 92.5$

L.F.H. $\quad 47 \pm 4 \quad 44$

Mand. Arc $26.2 \mp 4 \quad 29$

F.M.A $25.8 \pm 4 \quad 19$

$+0.48 \quad 0.1 \mathrm{~mm} . \quad 3.1 \mathrm{~mm} . \quad 3.7 \mathrm{~mm}$.

120 Facial Depth $87 \pm 3 \quad 90$

Facial Axis $90 \pm 3 \quad 91$

L.F.H. $\quad 47 \mp 4 \quad 40$

Mand. Arc $27 \pm 4 \quad 31$

F.M.A $\quad 25.3 \pm 4 \quad 18.5$

$+1.160 .3 \mathrm{~mm}$.

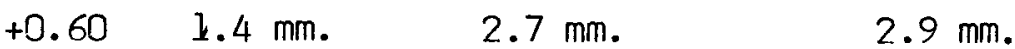

L.F.H. $\quad 47 \pm 4 \quad 45$

Mand. Arc $27 \mp 4$

F.M.A $23.3 \pm 4 \quad 20$ 
TABLE IV (continued)

\begin{tabular}{|c|c|c|c|c|c|c|c|}
\hline 1462 & $\begin{array}{l}\text { Facial Depth } \\
\text { Facial Axis } \\
\text { L.F.H. } \\
\text { Mand. Arc } \\
\text { F.M.A }\end{array}$ & $\begin{array}{l}88.6 \pm 3 \\
90 \pm 3 \\
47 \pm 4 \\
28 \pm 4 \\
24.3 \pm 4\end{array}$ & $\begin{array}{l}87 \\
90 \\
48 \\
28 \\
28\end{array}$ & -0.34 & $0.7 \mathrm{~mm}$. & -- & \\
\hline 767 & $\begin{array}{l}\text { Facial Depth } \\
\text { Facial Axis } \\
\text { L.F.H. } \\
\text { Mand. Arc } \\
\text { F.M.A }\end{array}$ & $\begin{array}{l}89 \pm 3 \\
90 \pm 3 \\
47 \pm 4 \\
29 \pm 4 \\
24 \pm 4\end{array}$ & $\begin{array}{l}88.5 \\
83 \\
55 \\
29 \\
36\end{array}$ & -1.50 & $1.2 \mathrm{~mm}$. & -- & \\
\hline 899 & $\begin{array}{l}\text { Facial Depth } \\
\text { Facial Axis } \\
\text { L.F.H. } \\
\text { Mand. Arc } \\
\text { F.M.A }\end{array}$ & $\begin{array}{l}87.6 \pm 3 \\
90 \pm 3 \\
47 \pm 4 \\
27 \pm 4 \\
25.3 \pm 4\end{array}$ & $\begin{array}{l}87.5 \\
83.5 \\
58 \\
17 \\
36\end{array}$ & -2.05 & $-2.9 \mathrm{~mm}$ & -- & \\
\hline 1807 & $\begin{array}{l}\text { Facial Depth } \\
\text { Facial Axis } \\
\text { L.F.H. } \\
\text { Mand. Arc } \\
\text { F.M.A }\end{array}$ & $\begin{array}{l}88.6 \pm 3 \\
90 \pm 3 \\
47 \pm 4 \\
28.5 \pm 4 \\
24.3 \pm 4\end{array}$ & $\begin{array}{l}94 \\
90 \\
42.3 \\
34 \\
13\end{array}$ & +1.42 & $3.8 \mathrm{~mm}$. & $1.5 \mathrm{~mm}$. & \\
\hline
\end{tabular}


TABLE IV (continued)

1051 Facial Depth $88.6+3$

Facial Axis $90 \div 3 \quad 96$

L.F.H. $\quad 47 \pm 4 \quad 42$

Mand. Arc $28.5+4 \quad 34$

F.M.A $24.3 \pm 4 \quad 20$

$+1.45 \quad 1.3 \mathrm{~mm} . \quad 2.3 \mathrm{~mm} . \quad 0.6 \mathrm{~mm}$.

906 Facial Depth $88.6 \pm 3 \quad 87$

Facial Axis $90 \pm 3 \quad 85$

L.F.H. $\quad 47 \pm 4$

Mand. Arc $28.5 \mp 4$

F.M.A $24.3 \pm 4$

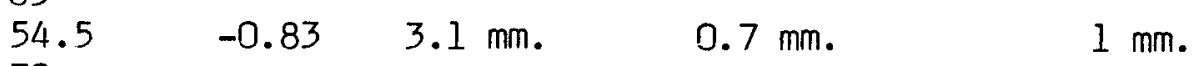

30

26

1279 Facial Depth

Facial Axis

$87.3+3$

92.5

L.F.H.

$90+3$

92.5

Mand. Arc

$47 \pm 4$

$26.5 \pm 4$

$25.6 \pm 4$

$+0.97 \quad 2.1 \mathrm{~mm}$.

F.M.A

45

29

21

834 Facial Depth $87.8+3$

Facial Axis $90 \pm 3 \quad 90$

L.F.H.

$47 \pm 4$

Mand. Arc

90
45

F.M.A

$27.2 \pm 4$

$25.1 \pm 4$

24

28

$-0.06 \quad 0.1 \mathrm{~mm}$.


TABLE IV (continued)

\begin{tabular}{|c|c|c|c|c|c|c|c|c|}
\hline 1234 & $\begin{array}{l}\text { Facial Depth } \\
\text { Facial Axis } \\
\text { L.F.H. } \\
\text { Mand. Arc } \\
\text { F.M.A }\end{array}$ & $\begin{array}{l}88.6 \\
90 \\
47 \\
28.5 \\
24.3\end{array}$ & $\begin{array}{l} \pm 3 \\
\pm 3 \\
\pm \\
\pm 4 \\
\pm 4 \\
\pm 4\end{array}$ & $\begin{array}{l}84 \\
84 \\
54 \\
22 \\
34\end{array}$ & -1.86 & $0.8 \mathrm{~mm}$. & $-0.4 \mathrm{~mm}$. & $0.8 \mathrm{~mm}$. \\
\hline 2691 & $\begin{array}{l}\text { Facial Depth } \\
\text { Facial Axis } \\
\text { L.F.H. } \\
\text { Mand. Arc } \\
\text { F.M.A }\end{array}$ & $\begin{array}{l}89.3 \\
90 \\
47 \\
29.5 \\
23.6\end{array}$ & $\begin{array}{l} \pm 3 \\
\pm 3 \\
\pm \\
\pm \\
\pm \\
\pm 4\end{array}$ & $\begin{array}{l}86.5 \\
85 \\
50 \\
32 \\
24.5\end{array}$ & -0.59 & $2.6 \mathrm{~mm}$. & $4.1 \mathrm{~mm}$ & $3.3 \mathrm{~mm}$. \\
\hline 699 & $\begin{array}{l}\text { Facial Depth } \\
\text { Facial Axis } \\
\text { L.F.H. } \\
\text { Mand. Arc } \\
\text { F.M.A }\end{array}$ & $\begin{array}{l}87 \\
90 \\
47 \\
26 \\
26\end{array}$ & $\begin{array}{l} \pm 3 \\
\pm 3 \\
\pm \\
\pm \\
\pm \\
\pm 4\end{array}$ & $\begin{array}{l}84 \\
89 \\
47 \\
23 \\
30.5\end{array}$ & -0.64 & -- & $2.6 \mathrm{~mm}$ & $2.1 \mathrm{~mm}$. \\
\hline 229 & $\begin{array}{l}\text { Facial Depth } \\
\text { Facial Axis } \\
\text { L.F.H. } \\
\text { Mand. Arc } \\
\text { F.M.A }\end{array}$ & $\begin{array}{l}87 \\
90 \\
47 \\
26 \\
26\end{array}$ & $\begin{array}{l} \pm 3 \\
\pm 3 \\
\pm \\
\pm \\
\pm \\
\pm 4\end{array}$ & $\begin{array}{l}84 \\
89 \\
47 \\
23 \\
30.5\end{array}$ & -0.64 & -- & $2.8 \mathrm{~mm}$ & $1.8 \mathrm{~mm}$. \\
\hline
\end{tabular}


TABLE IV (continued)

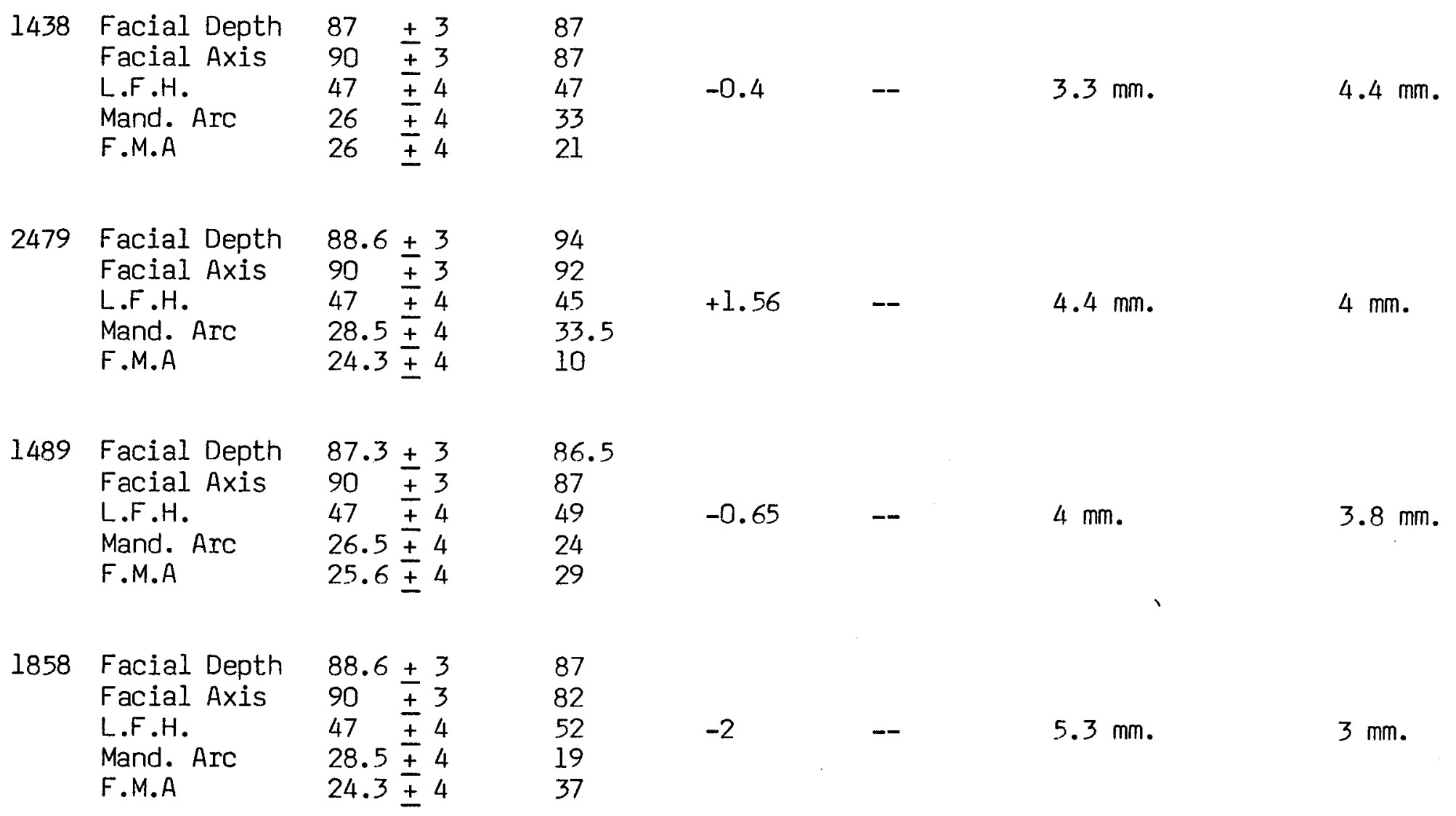


TABLE IV (continued)

\begin{tabular}{|c|c|c|c|c|c|c|c|c|}
\hline 2141 & $\begin{array}{l}\text { Facial Depth } \\
\text { Facial Axis } \\
\text { L.F.H. } \\
\text { Mand. Arc } \\
\text { F.M.A }\end{array}$ & $\begin{array}{l}86 \\
90 \\
47 \\
26 \\
27\end{array}$ & $\begin{array}{l} \pm 3 \\
\pm 3 \\
\pm 4 \\
\pm 4 \\
\pm 4\end{array}$ & $\begin{array}{l}91 \\
88 \\
50 \\
19 \\
27\end{array}$ & -0.30 & -- & $4.1 \mathrm{~mm}$. & $4.7 \mathrm{~mm}$ \\
\hline 1978 & $\begin{array}{l}\text { Facial Depth } \\
\text { Facial Axis } \\
\text { L.F.H. } \\
\text { Mand. Arc } \\
\text { F.M.A }\end{array}$ & $\begin{array}{l}87 \\
90 \\
47 \\
26 \\
26\end{array}$ & $\begin{array}{l} \pm 3 \\
\pm 3 \\
\pm 4 \\
\pm 4 \\
\pm 4\end{array}$ & $\begin{array}{l}88 \\
85 \\
47 \\
25 \\
28\end{array}$ & -0.42 & -- & $-0.6 \mathrm{~mm}$ & $-2.6 \mathrm{~mm}$ \\
\hline 641 & $\begin{array}{l}\text { Facial Depth } \\
\text { Facial Axis } \\
\text { L.F.H. } \\
\text { Mand. Arc } \\
\text { F.M.A }\end{array}$ & $\begin{array}{l}87.8 \\
90 \\
47 \\
27 \\
25\end{array}$ & $\begin{array}{l} \pm 3 \\
\pm 3 \\
\pm 4 \\
\pm 4 \\
\pm 4\end{array}$ & $\begin{array}{l}86 \\
90 \\
51 \\
21 \\
27\end{array}$ & -0.72 & -- & $3.8 \mathrm{~mm}$ & $4.3 \mathrm{~mm}$ \\
\hline 2229 & $\begin{array}{l}\text { Facial Depth } \\
\text { Facial Axis } \\
\text { L.F.H. } \\
\text { Mand. Arc } \\
\text { F.M.A }\end{array}$ & $\begin{array}{l}86.5 \\
90 \\
47 \\
26 \\
26.5\end{array}$ & $\begin{array}{l} \pm 3 \\
\pm 3 \\
\pm 4 \\
\pm 4 \\
\pm 4\end{array}$ & $\begin{array}{l}90 \\
90 \\
40 \\
23 \\
23\end{array}$ & +0.56 & -- & $-1.3 \mathrm{~mm}$ & $-1.5 \mathrm{~mm}$. \\
\hline
\end{tabular}


TABLE IV (continued)

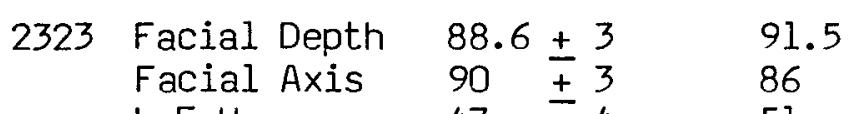

$\begin{array}{lll}\text { L.F.H. } & 47 \pm 4 & 51 \\ \text { Mand. Arc } & 28.5 \pm 4 & 28\end{array}$

$\begin{array}{lll}\text { Mand. Arc } & 28.5 \pm 4 & 28 \\ \text { F.M.A } & 24.3 \pm 4 & 28.6\end{array}$ 


\section{APPROVAL SHEET}

The thesis submitted by Robin Sandstrom Papaconstantinou, D.D.S. has been read and approved by the following committee:

Klapper, Lewis, D.M.D., M.SC.D., D.SC.

Assistant Professor and Chairman, Orthodontic Department, Loyola.

Wortel, John P., D.D.S.

Assistant Professor, Oral and General Pathology Department, Loyola.

Beery, James G., D.D.S., M.SC.D.

Assistant Professor, Orthodontic Department, Loyola

The final copies have been examined by the director of the thesis and the signature which appears below verifies the fact that any necessary changes have been incorporated and that the thesis is now given final approval by the Committee with reference to content and form.

The thesis is therefore accepted in partial fulfillment of the requirements for the degree of Master of science.
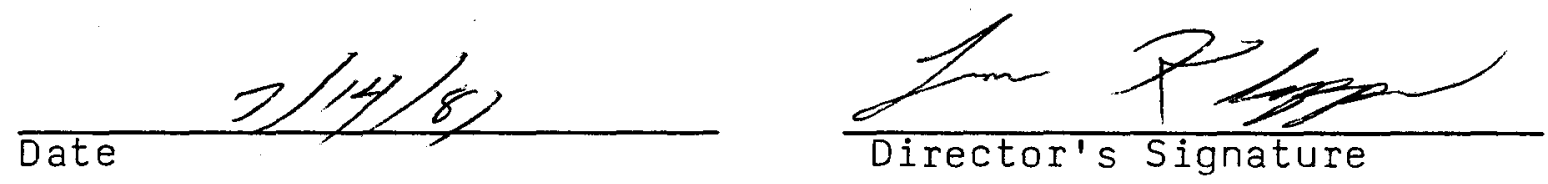